[Review]

\title{
二维炭基多孔材料的合成及应用
}

\author{
贺 雷 张向倩 陆安慧 ${ }^{*}$ \\ (大连理工大学化工学院, 精细化工国家重点实验室, 辽宁大连 116024)
}

\begin{abstract}
摘要: 二维材料是指厚度在纳米尺度, 且在两个维度(长和宽)具有较大尺寸的材料。与块体材料相比, 二维 材料最大的特点是具有极高的表面/体积比, 有利于传质、传热和离子扩散, 因而在吸附、催化以及储能等 领域有广泛的应用。近年来, 随着石墨烯引发的二维材料研究浪潮, 二维炭基多孔材料成为全世界关注的研 究热点。而二维炭基材料的孔结构是影响其性能的关键因素。本文介绍了近年来二维炭基多孔材料的合成方 法, 包括炭纳米片及炭-无机复合纳米片的制备, 讨论了制备条件对材料孔结构的影响。在此基础上, 着重 介绍了二维炭基材料在吸附、多相催化及储能方面的应用。最后, 对新型炭基二维材料开发中仍存在的关键 科学问题进行了总结和展望。
\end{abstract}

关键词: 二维材料; 炭; 孔结构; 合成方法; 吸附; 催化; 储能 中图分类号: 0643

\section{Two-Dimensional Carbon-Based Porous Materials: Synthesis and Applications}

\author{
HE Lei ZHANG Xiang-Qian LU An-Hui* \\ (State Key Laboratory of Fine Chemicals, School of Chemical Engineering, Dalian University of Technology, \\ Dalian 116024, Liaoning Province, P. R. China)
}

\begin{abstract}
Two-dimensional (2D) materials possess nanoscale thickness with large aspect ratios on the other two dimensions. The ultrahigh surface-to-volume ratio of 2D materials is the most important property different from their bulk counterparts, and is beneficial for mass and heat transport, and ion diffusion. Among the various 2D materials, carbon-based materials have attracted tremendous attentions since the first explosive research on graphene. Therefore, they provide opportunities for applications in adsorption, catalysis, and electrical energy storage. The porous structure of such carbon materials is a key influence on the properties of these 2D materials. This review focuses on recent developments in synthesis strategies for 2D carbon-based materials, especially the preparation of carbon nanosheets and carbon-inorganic hybrids/composites nanosheets. The main factors influencing the porous structure of the material are discussed for each method. Applications of the materials are introduced, mainly in the fields of adsorption, heterogeneous catalysis, and electrical energy storage. Finally, the leading-edge issues of novel 2D carbon-based materials for the future are discussed.
\end{abstract}

Key Words: Two-dimensional material; Carbon; Porous structure; Synthesis strategy; Adsorption; Catalysis; Electrical energy storage

\section{Introduction}

Two-dimensional (2D) materials are materials consisting of nano-scale thickness with larger width and length for the other two dimensions (the ratio of width/thickness or length/thickness larger than 50). Since the production of single layered graphene in $2004^{1}$, 2D materials are nowadays under rapid development ${ }^{2}$. Besides

Received: October 21, 2016; Revised: December 20, 2016; Published online: December 20, 2016.

*Corresponding author. Email: anhuilu@dlut.edu.cn; Tel: +86-411-84986112.

The project was supported by the National Natural Science Foundation of China $(21225312,21403027,21506022)$.

国家自然科学基金(21225312, 21403027, 21506022)资助项目

(c) Editorial office of Acta Physico-Chimica Sinica 
single-atomic-thick graphene ${ }^{3}$ and boron nitride $(\mathrm{BN})^{4}$, other compounds with single-polyhedral-thickness containing $\mathrm{O}, \mathrm{S}, \mathrm{N}$ atoms can also be classified as 2D materials, including transition metal oxides (TMOs) ${ }^{5}$, transition metal dichalcogenides (TMDs) ${ }^{6}$, layered double hydroxides $(\mathrm{LDH})^{7,8}$, perovskite materials ${ }^{9}$, and single-layered zeolites ${ }^{10-12}$. The ultrahigh surface-to-volume ratio feature of the 2D materials is beneficial for mass and heat transport ${ }^{13}$. Due to the unique physical structure and tunable chemical property, they are widely employed in the applications of adsorption ${ }^{14}$, heterogeneous catalysis ${ }^{15-17}$, photonic and electronic industries ${ }^{18-20}$, analysis ${ }^{21}$, and energy storage ${ }^{22,23}$.

Among various 2D nanostructures, carbon-based materials have attracted tremendous attentions due to their broad availability, excellent electric and thermal conductivity, chemical stability, and relatively easy functionalization or hybridization ${ }^{24,25}$. Here, 2D carbon-based materials are defined as the materials composed of carbon and other inorganic units with 2D structures. Carbon nanosheets (CNSs) are representative for this type of materials, which have been widely studied in energy-related and environmental applications. During the past decade, a rapid development of synthesis strategies has provided capability of preparing CNSs with controllable thickness, tunable pore size and surface area, and specific surface functional groups. So far, there are five major synthesis strategies, which will be discussed in detail in Section 2 (Fig.1). To be noticed, the pore structure is the key factor that influences the performance of the carbon-based materials in many fields, such as adsorption, catalysis, and electronic devices. In general, micropores are the crucial contributors for large surface area, high adsorption capacity, and high electrical capacitance. However, for conventional porous carbons, the kinetic problems of micropores hinder their applications. It is a supplement to the conventional methods which prepare the porous carbons by introducing mesopores or even macropores into the entire structure, to improve the mass and heat transport.

This review will focus on the most recent development of 2D

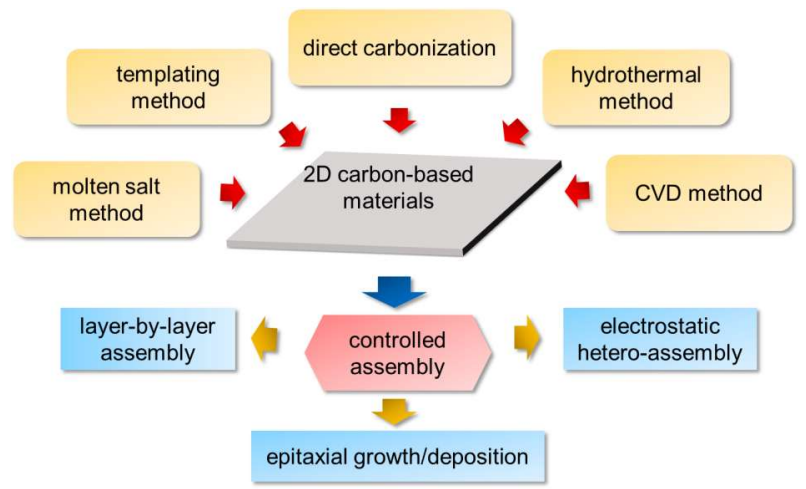

Fig.1 Synthesis strategies for 2D carbon-based materials

carbon-based porous materials. The correlation of the pore structures and the synthesis methods will be discussed. It will provide insight into ways for facile design of novel 2D carbonbased materials with certain pore structures. On this basis, the assembled structures (including carbon monolith, thin films and hybrids/composites) by 2D materials will be introduced and classified according to their composition. Furthermore, the applications of the 2D carbon-based porous materials will be introduced focusing on adsorption, heterogeneous catalysis, analysis, and electrical energy storage.

\section{Synthesis strategies for 2D porous carbon materials}

Carbon materials with 2D structure, usually defined as CNSs, have been synthesized by various methods, including chemical vapor deposition (CVD) of gaseous precursors, templating and self-assembly method in liquid phase, molten salt route, direct carbonization, etc. The thickness, degree of graphitization, and porous structure of a CNS can be controlled by changing synthesis conditions. Furthermore, the chemical composition of CNSs can be adjusted by varying precursors, synthesis conditions, and posttreatment processes. This section provides a summary of five main

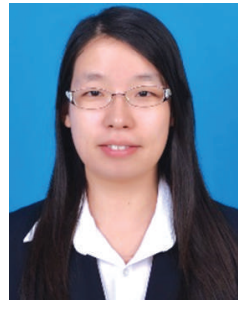

$\mathrm{HE}$ Lei received her $\mathrm{PhD}$ degree from Dalian Institute of Chemical Physics, Chinese Academy of Sciences in 2014. Since 2014, she has been working in Dalian University of Technology as a lecturer and a postdoctoral researcher. Her research interests now mainly focus on catalytic $\mathrm{CO}_{2}$ conversion processes.

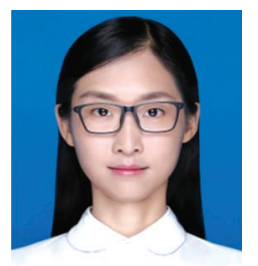

ZHANG Xiang-Qian received her Master degree from Dalian University of Technology in 2013. She is currently a $\mathrm{PhD}$ student in Prof. LU An-Hui's group since 2014. Her research focuses on synthesis and application of porous carbon nanomaterials with designed porosity and controlled morphology.

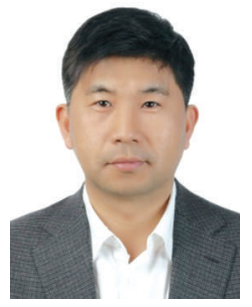

LU An-Hui received his $\mathrm{PhD}$ degree from the Institute of Coal Chemistry, Chinese Academy of Sciences in 2001. After postdoctoral work (as a Max Planck research fellow and Alexander von Humboldt fellow) in the group of Prof. F. Schüth at Max- Planck-Institut für Kohlenforschung, he was promoted to group leader in 2005 . He is currently a professor at the State Key Laboratory of Fine Chemicals, School of Chemical Engineering, Dalian University of Technology since 2008. Since 2015, he has been appointed as the Dean of the School of Chemical Engineering. His research interests include synthesis of porous materials for heterogeneous catalysis, adsorption, energy storage and conversion. 
strategies for the preparation of CNSs. Especially, the factors influencing porous structures will be discussed in detail for each strategy. Here, microporous carbon nanosheets are defined according to the ratio of micropore volume (accounts for over $60 \%$ of the total pore volume). Similarly, mesoporous carbon nanosheets are also describing the material with dominant amount of mesopores (over $60 \%$ ). Besides, other carbon nanosheets, possessing hierarchical porous structures containing micropores, mesopores, or even macropores, are also introduced in this section, including the structures fabricated or assembled by carbon nanosheets.

\subsection{Templating method}

One of the most powerful methods for preparing porous CNSs is the templating method. In principle, a template can be any substance as long as having sheet-like structures, including soft and hard templates. Various porous carbon materials have been prepared using soft templates ${ }^{26}$. However, the sheet-like soft templates are very difficult to synthesize, which in turn leads to commonly hard-template method for preparing CNSs. Various oxide materials, including $\mathrm{SnO}_{2}, \mathrm{ZnO}, \mathrm{MgO}$, have been employed as hard templates ${ }^{27-29}$. Graphene oxides (GOs) have also been successfully used as shape-directing agent for the preparation of $\mathrm{CNSs}^{14}$. Typically, a templating synthetic procedure includes the preparation of carbon precursor/template composite, carbonization, and removal of the template ${ }^{30}$. To be noted, using carbonbased nanosheets (e.g., GO) as templates will leave out the template removal process. Generally, the pore structures are mainly determined by the original structure of the templates, which could also be adjusted by the surfactants and carbonization conditions.

\subsubsection{Microporous carbon nanosheets}

Graphene oxides with a heavily oxygenated surface can be chosen as a shape-directing agent for preparing microporous carbon nanosheets. Its surface is negatively charged which has been confirmed by zeta potential analysis ${ }^{31}$. By means of the electrostatic interaction, surface-engineering on the GO sheets is expected to produce new hybrid products using different carbon precursors. For example, sandwich-type microporous hybrid carbon nanosheets (MHCNs) consisting of graphene and microporous carbon layers were fabricated using graphene oxides as shape-directing agent, amino acids as bridging agent, and the insitu formed poly(benzoxazine-co-resol) as carbon precursor (Fig.2) ${ }^{32}$. A strong electrostatic interaction between asparagine molecules and GO rapidly in-situ reacted with the resorcinol and formaldehyde, ending with uniform poly(benzoxazine-co-resol) layer grown on both sides of the GO sheets. The overall thickness of the nanosheets can be tuned from 20 to $200 \mathrm{~nm}$ according to a fitted linear correlation between the carbon precursor/GO mass ratio and the coating thickness.

Nitrogen-doped carbon nanosheets are claimed to possess excellent performances in adsorption and supercapacitors, which can be synthesized by employing nitrogen-containing carbon source in the templating process. For example, nitrogen-doped sandwich-
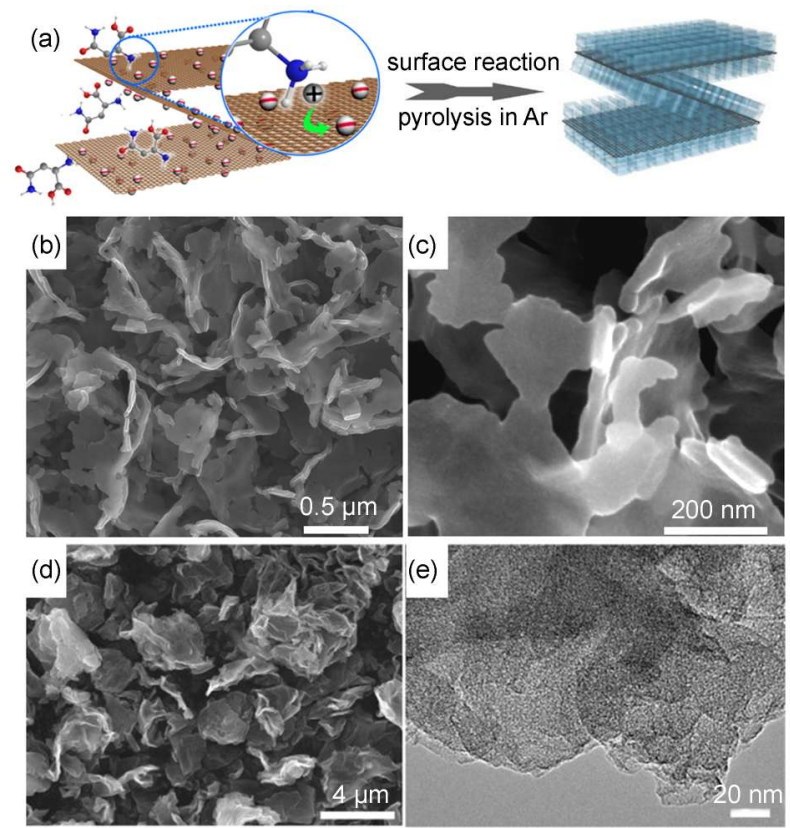

Fig.2 (a) Schematic of the formation of carbon nanosheets (MHCNs) using GOs as templates; $(b, c)$ scanning electron microscopy (SEM) images of $\mathrm{MHCNs}^{32}$; (d, e) SEM and transmission electron microscopy (TEM) images of NPCG $^{33}$

like porous carbon nanosheets were prepared through carbonization of graphene/polyaniline hybrid materials ${ }^{33}$. The final products showed interconnected microporous structure, with the nitrogen content of $12.7 \%$ ( $a$, atomic fraction), the surface area of $410.4 \mathrm{~m}^{2} \cdot \mathrm{g}^{-1}$ and the volumetric density of $0.94 \mathrm{~g} \cdot \mathrm{cm}^{-3}$. The content of graphene in the final products is in the range of $25 \%-$ $31 \%$ ( $w$, mass fraction).

Ionic liquids (ILs) have many excellent features, such as good solubility for chemicals, excellent thermal stability and negligibly small vapor pressure. Therefore, the ILs containing nitrile groups can be used as a heteroatom source for preparing carbon materials, which may not only facilitate the solubility of carbon precursors, but may also serve as a heteroatom source for a doping agent ${ }^{34}$. An aqueous solution of $2 \mathrm{D}$ nitrogen-doped microporous carbon sheets with precisely controlled thickness, can be prepared using ionic liquid functionalized graphene oxide (IL-functionalized GO) sheets as a shape-directing agent and a resorcinol/formaldehyde polymer as the carbon precursor ${ }^{35}$. The ionic liquid was selected to stabilize the isolated GO sheets and to functionalize them in an aqueous solution. This type of materials is classified as microporous carbon sheets rather than graphene or graphene-based sheets because the prepared sheets contain very small amounts of graphene, from $0.26 \%$ to $2.72 \%(w)$, and have a graphene inner layer and a carbon coating on both sides.

Recently, novel porous polymers with 2D structures have been prepared, which could also be used as self-sacrificing template. Xiang et al. ${ }^{36,37}$ employed 2D covalent organic polymers (COPs) as self-sacrificing template to synthesize nitrogen-doped holey graphene-like carbons. Using different $\mathrm{N}$-containing precursors, the locations of heteroatoms were precisely controlled with certain 
porosity structures.

\subsubsection{Mesoporous carbon nanosheets}

In general, micropores are the crucial contributors for large surface area. However, the ion diffusion and mass transfer in the micropores is often restricted due to the limited pore size and pore volume. Therefore, the construction of carbon nanosheets with a mesoporous domain is welcomed and should benefit for their applications.

Using mesoporous oxide nanosheets as hard templates can generate CNSs with mesoporous structure originated from the templates. For example, $\mathrm{MgO}$ is one of the most common hard templates for the synthesis of CNSs, which was produced by a boiling treatment for $\mathrm{MgO}$ particles with a subsequent calcination process $^{27}$. Afterwards, the porous $\mathrm{MgO}$ sheets were coated with carbon source by self-assembly approach. After carbonization and removal of the $\mathrm{MgO}$ template, carbon nanosheets can be obtained with similar structure as the original porous $\mathrm{MgO}$ sheets. The carbon nanosheets had a high surface area of $883 \mathrm{~m}^{2} \cdot \mathrm{g}^{-1}$ as well as pillared mesoporous structures $(6-8 \mathrm{~nm})$. Similarly, Wang and his co-workers ${ }^{22}$ have prepared a two-dimensional mesoporous carbon sheet-like framework (MCSF) material using mesoporous $\mathrm{SiO}_{2}$ nanosheet as template and coal tar pitch as carbon precursor. Thus, MCSF possessed a thin carbon sheet structure and abundant mesopores with sizes centered at 2.2 and $15 \mathrm{~nm}$, respectively. However, the synthesis procedure is somewhat complex and the carbon particles have a relatively low surface area $\left(582.7 \mathrm{~m}^{2} \cdot \mathrm{g}^{-1}\right)$ and an unsatisfactory entire porosity.

Biomass resources can also be used as templates for synthesizing carbon nanosheets. Zhang and coworkers ${ }^{38}$ reported a facile and scalable in-situ synthetic strategy (simultaneous template- graphitization) to fabricate porous carbon sheets (PMCSs) using biomass agar as template, in which carbon-stabilized $\mathrm{Fe} / \mathrm{Fe}_{3} \mathrm{C}$ nanoparticles were homogeneously embedded. In the synthesis (Fig.3), the graphitic catalyst precursor $\left(\mathrm{Fe}\left(\mathrm{NO}_{3}\right)_{3}\right)$ and template agent $\left(\mathrm{Al}\left(\mathrm{NO}_{3}\right)_{3}\right)$ were introduced simultaneously into the agar hydrogel through the coordination of the metal precursor with the functional groups on agar, thus resulting in simultaneous realization of the template and graphitization of the carbon source under heat treatment. This PMCS possessed relatively high surface area $\left(1023.2 \mathrm{~m}^{2} \cdot \mathrm{g}^{-1}\right)$ with the average pore diameter of $12.5 \mathrm{~nm}$.

Although graphite layers have unique properties, such as excellent electric conductivity, the low surface area and nonporous structure limit their applications. To make abundant porous structures, carbon coated graphene composites have been developed. Using expandable graphite (EG) as the template, mesoporous-carbon-coated graphite nanosheet (GNS@MC) composites have been synthesized by the intercalation of resol prepolymer into the interlayers of EG under vacuum-assisted conditions, followed by the exfoliation of EG through in-situ polymerization, the growth of resol under hydrothermal conditions, and carbonization under $\mathrm{Ar}^{39}$. The carbon product possessed a specific surface area of $432.3 \mathrm{~m}^{2} \cdot \mathrm{g}^{-1}$ and bimodal mesopores with detectable sizes of 2.3 and $9.2 \mathrm{~nm}$. Another example is the synthesis of nitrogen-doped mesoporous graphene nanosheets using $\mathrm{GO}$ as template and $\mathrm{NH}_{2} \mathrm{CN}$ as nitrogen source ${ }^{40}$. The as-obtained carbon nanosheets possessed high surface area with an average pore size of around $6.3 \mathrm{~nm}$, which can be attributed to the abundant wrinkled structures originated from the carbonization process. The $\mathrm{N}$ content in the final product was $9.96 \%(w)$.

Besides, the addition of GO can alter the structure of carbon
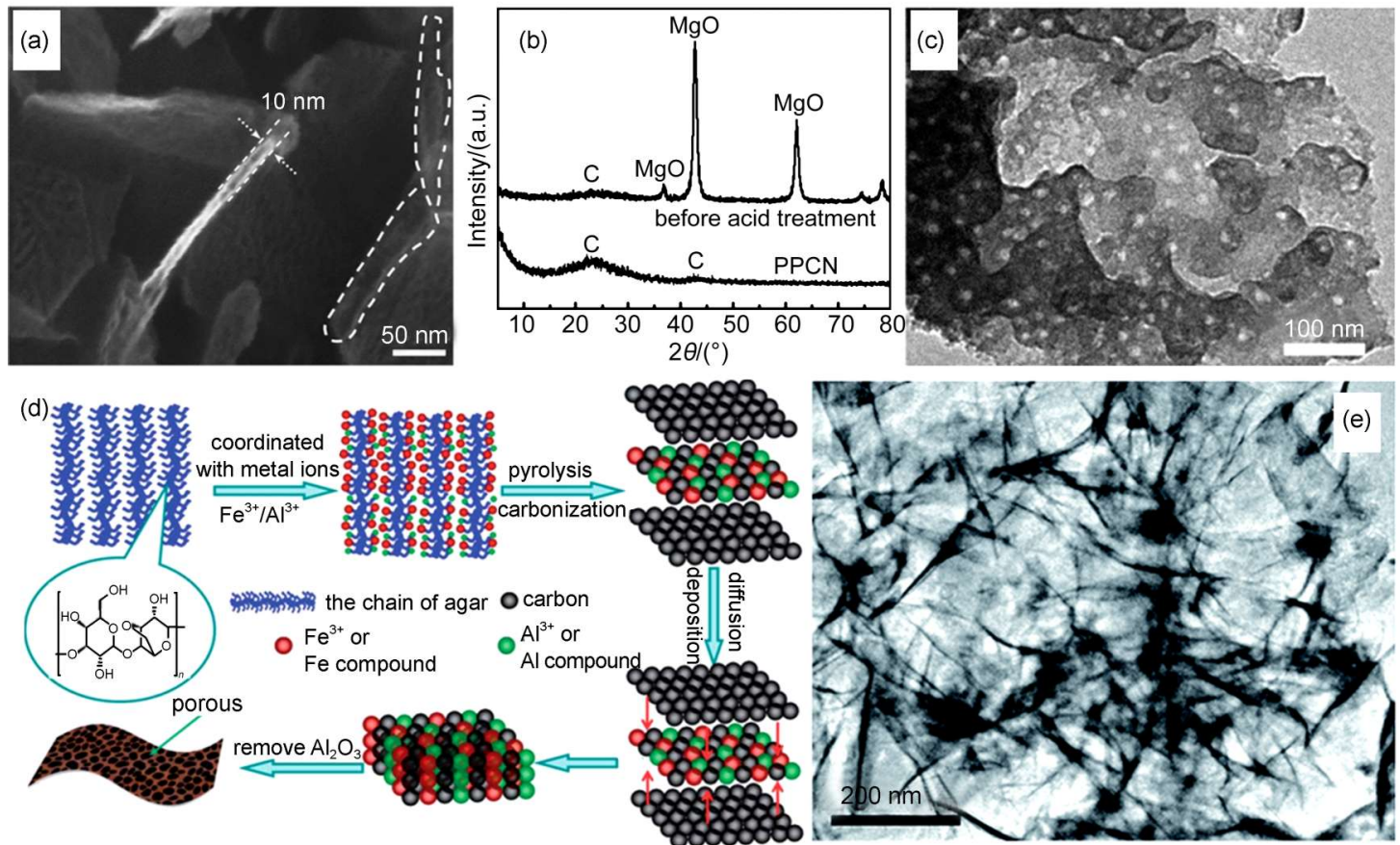

Fig.3 (a) SEM image of PPCN; (b) X-ray diffraction (XRD) patterns of PPCN before and after acid treatment ${ }^{27}$; (c) TEM image of $\mathrm{MCSF}^{22}$; (d) mechanism of the decomposition of agar and formation of PMCS; (e) TEM image of PMCS 
materials. Hydrothermal carbonization (HTC) of biomass such as glucose and cellulose typically produces micrometer-sized carbon spheres. However, adding a very small amount of GO (e.g., $1: 800$ (mass ratio)) can significantly alter the morphology of its HTC product. HTC of GO and glucose resulted in thick platelets of glucose-derived carbon-coated reduced graphene oxide ( $r-\mathrm{GO}$ ) sheets at low GO concentration ${ }^{41}$. GO sheets can act as nucleation and growth sites for seeding the carbonization product of glucose. Glucose solution containing dispersed GO sheets was hydrothermally carbonized to form a brown char-like intermediate product, and finally converted to porous nanosheet composite by two-step chemical activation using $\mathrm{KOH}^{42}$. The composite had a relatively high packing density of $0.3 \mathrm{~g} \cdot \mathrm{cm}^{-3}$ and large specific surface area of $2106 \mathrm{~m}^{2} \cdot \mathrm{g}^{-1}$, as well as containing plenty of mesopores.

Nevertheless, the synthesis process for GO is tedious and expensive, which is the main limitation for its large-scale applications. Other cheap layer-structured materials with facile syntheses are widely selected as templates to prepare CNSs, such as vermiculite $^{43}$, halloysite ${ }^{44}$ and montmorillonite ${ }^{45}$. Take halloysite as an example, which can be selected to synthesize amorphous mesoporous carbon sheets by using polypyrrole ${ }^{44}$ or furfuryl alcohol ${ }^{46}$ as carbon precursors.

\subsection{Molten salt route}

Molten salt route is an easy and efficient method for the syn- thesis of carbon nanosheets with high surface area, where the molten salt acts as solvents and porogen in this process ${ }^{47}$. Depending on the nature of the salt, the carbonization temperature ranges from 100 to $1000{ }^{\circ} \mathrm{C}^{48}$. Thus, several types of carbon nanosheets from simple porous frameworks to complex heteroatoms (nitrogen or sulfur) doping materials have been synthesized $^{49}$. Their physical and chemical properties are tunable by changing the salts or carbon precursors.

\subsubsection{Microporous carbon nanosheets}

$\mathrm{He}$ and coworkers have recently synthesized a series of porous carbon nanosheets with high nitrogen content using melamine and terephthalaldehyde as carbon precursors through the Schiff-base reaction in a molten salt medium (Fig.4) ${ }^{50}$. As the mole ratio of terephthalaldehyde to melamine reaching 1.0 , the nitrogen content of the obtained carbon sheet was $30.51 \%(w)$, which was much higher than that in other nitrogen- rich carbon materials. The specific surface area for all the carbons derived from the molten salt system was at least a tenfold increase compared with the sample prepared without salt. The results indicated that the salt reaction medium, possibly as a porogen, was the key factor for enlarging the specific surface area. It is believed that the ionized environment created by molten salt efficiently prevented the product from agglomeration due to the high viscosity and played a template role in directing the formation of 2D structure. Furthermore, the concentration of the carbon precursor can also
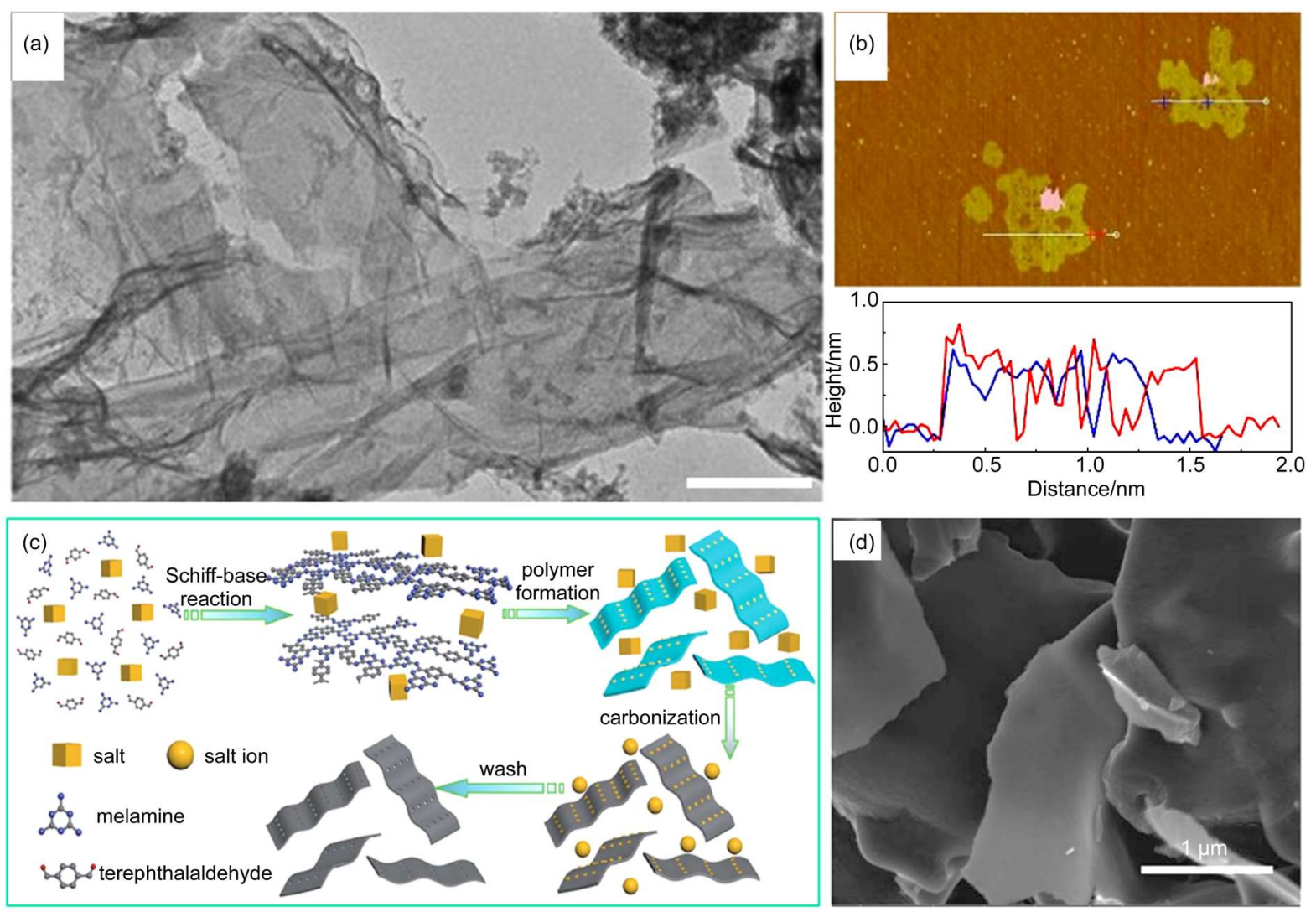

Fig.4 Typical (a) TEM and (b) atomic force microscopy (AFM) images for the graphene-like thin carbon layers synthesized in $\mathrm{KClO}_{3} @ \mathrm{LiCl} / \mathrm{KCl}$ at $900{ }^{\circ} \mathrm{C}$ (scale bar: $\left.0.5 \mu \mathrm{m}\right)^{49}$; (c) preparation strategy of carbon nanosheets using molten salt method (LiCl-KCl) and (d) the corresponding SEM image $\mathrm{e}^{50}$ 
impact the formation of sheet-like structure ${ }^{51}$. For example, along with the decrease in the precursor concentration of glucose, the fraction of sheet structures retained in the products increased remarkably, which means that the molten salt is able to dissolve the intermediates and convert completely the carbon source to graphene layers. It has been proved that the salts played an important role in the formation of the microstructure as well as the porosity of the carbon nanosheets. Several publications attributed a template role to the intentionally added salt during the synthesis of carbons ${ }^{47,48,52}$. However, the mechanism for the formation of $2 \mathrm{D}$ carbon sheets is still unclear and potentially very attracting.

\subsubsection{Mesoporous carbon nanosheets}

The carbon nanosheets prepared from molten salt route enabled a one-step synthesis of highly porous heteroatom-doped carbons with specific surface areas up to $2000 \mathrm{~m}^{2} \cdot \mathrm{g}^{-1}$. For example, Zhang and co-workers ${ }^{53}$ recently fabricated the graphene-like carbon sheets with well-defined mesopores $(\sim 3.5 \mathrm{~nm})$, high specific surface area (up to $2607 \mathrm{~m}^{2} \cdot \mathrm{g}^{-1}$ ), and high pore volume (up to 3.12 $\mathrm{cm}^{3} \cdot \mathrm{g}^{-1}$ ) using polyimide chemistry in the molten salt medium. In this process, abundant pyromellitic dianhydride and aromatic diamine undergo polycondensation following carbonization in molten $\mathrm{KCl}-\mathrm{ZnCl}_{2}$. The in-situ formed linear aromatic polyimide with a $s p^{2}$ hybridized carbon skeleton can be directly coupled and rearranged into a 2D graphene-like nanosheet around the "salt scaffold". The nitrogen atoms in amine also provided the as-obtained carbon materials with uniform foreign atoms (nitrogen content $\sim 6 \%(a)$ ). Furthermore, holey carbon sheets with welldispersed and through-plane nanoholes (diameter: 5-10 nm) can be produced by using different monomers.

\subsubsection{Other porous carbon structures}

In order to synthesize carbon nanosheets even more conveniently and economically, Fellinger and co-workers ${ }^{54}$ introduced an ionothermal carbonization via hot injection in molten $\mathrm{ZnCl}_{2}$ using ethylene glycol (EG) and glycerol as carbon precursors. To be noted, due to the very fast pyrolytic monomer decomposition in Schlenck-type reactor at high temperatures (up to $550{ }^{\circ} \mathrm{C}$ ), highly volatile but cheap organic solvents can be used as carbon precursors (such as EG). Interestingly, all organic solvents were successfully converted into carbonaceous nanomaterials with spherical, sheet-like, and branched nanofibrous morphologies and with high yields. When heteroatom-containing solvents were used, the doping levels reached up to $14 \%(w)$ nitrogen and $13 \%(w)$ sulfur. From the same group, the fabrication of vertically aligned carbon nanosheets (CNSs) and metal carbide@CNS composites were also fabricated via a salt templating induced self-assembly ${ }^{52}$. This approach allows for versatile fabrication of the carbon nanostructures and a range of hybrid materials, e.g., metal carbide nanoparticles rigidly embedded into the graphitic carbon nanosheets.

\subsection{Direct carbonization and/or activation}

As described above, the templating and molten salt methods are two of the most efficient strategies for preparing 2D carbon-based materials. However, the necessity of templating removing or salt recycling somewhat complexes the preparation process. Therefore, the development of facile synthesis procedures for producing porous carbon nanosheets is still desirable and attractive. Direct carbonization is a one-step method for preparing carbon materials at high temperatures, which can be combined with the activation process at the same time. The precursors can be widely available substance, such as organic salts, nitrides, resin, biomass, etc. The porous structure of the obtained products can be tuned by using different carbon precursors, adding activators, or changing carbonization conditions.

\subsubsection{Microporous carbon nanosheets}

Recently, Sevilla et al. ${ }^{55}$ reported an easy, one-step procedure for the synthesis of highly porous interconnected carbon nanosheets with a thickness of $<80 \mathrm{~nm}$, which was based on the carbonization of an organic salt (i.e., potassium citrate) at a temperature in the range of $750-900{ }^{\circ} \mathrm{C}$. The porosity of the carbon nanosheets essentially consisted of micropores distributed at $0.7-0.85 \mathrm{~nm}$ and $0.95-1.6 \mathrm{~nm}$. Importantly, the micropore sizes of both systems can be enlarged by simply increasing the carbonization temperature. Furthermore, the carbon nanosheets possess specific surface areas in the range of $1400-2200 \mathrm{~m}^{2} \cdot \mathrm{g}^{-1}$. Similarly, using sodium gluconate as the organic salt, highly porous carbon nanosheets were obtained after carbonization at $700-900{ }^{\circ} \mathrm{C}^{56}$. The as-prepared carbon nanosheets have a large aspect ratio (length/thickness $\approx 10^{2}-10^{3}$ ), a thickness within the range of $40-200 \mathrm{~nm}$, surface areas $\left(S_{\mathrm{BET}}\right)$ of up to $1390 \mathrm{~m}^{2} \cdot \mathrm{g}^{-1}$, and a porosity with a hierarchical organization. Importantly, the textural properties can be substantially enhanced ( $S_{\text {BET }}$ up to $1890 \mathrm{~m}^{2}$. $\mathrm{g}^{-1}$ ) via an additional activation step.

Bourlinos has reported a direct synthesis of ultrathin carbon nanosheets by the solid-state pyrolysis of betaine $\left(\left(\mathrm{CH}_{3}\right)_{3} \mathrm{~N}^{+} \mathrm{CH}_{2} \mathrm{COO}^{-}\right.$, a zwitterionic organic compound widely distributed in nature $)^{57}$. The nanosheets are less than $6 \mathrm{~nm}$ in thickness and $1-5 \mu \mathrm{m}$ in lateral dimensions, highly graphitized, contain polar functional groups on the surface, and possess a specific surface area $\left(\sim 100 \mathrm{~m}^{2} \cdot \mathrm{g}^{-1}\right)$. Moreover, the solid state pyrolysis of other betaine- based compounds (e.g., betaine hydrochloride) can also produce carbon nanosheets of similar dimensions, however, with much lower yields $(<0.5 \%)$.

\subsubsection{Mesoporous carbon nanosheets}

The one-step activation and nitrogen-doping combination method is also developed for preparing nitrogen-doped graphenelike carbon nanosheets (N-CNSs) (Fig.5) ${ }^{58}$. Macroporous anion exchange resin was used as carbon precursor and nitrogen source. The combination of $\mathrm{Ca}(\mathrm{OH})_{2}$ and $\mathrm{NH}_{4} \mathrm{Cl}$ performed as both activator and nitrogen source. The as-prepared N-CNS exhibits a porous, loose, ultrahigh pore volume $\left(3.19 \mathrm{~cm}^{3} \cdot \mathrm{g}^{-1}\right)$ and highly wrinkled morphology. By the same research group, highly crumpled nitrogen-doped graphene-like nanosheets with a specific surface area of $1169 \mathrm{~m}^{2} \cdot \mathrm{g}^{-1}$ and relatively large pore volume of $2.58 \mathrm{~cm}^{3} \cdot \mathrm{g}^{-1}$ were prepared from a macroporous resin via simultaneous urea gasification expansion and $\mathrm{CaCl}_{2}$ activation methods $^{59}$. The pore sizes of the sheets were distributed narrowly 


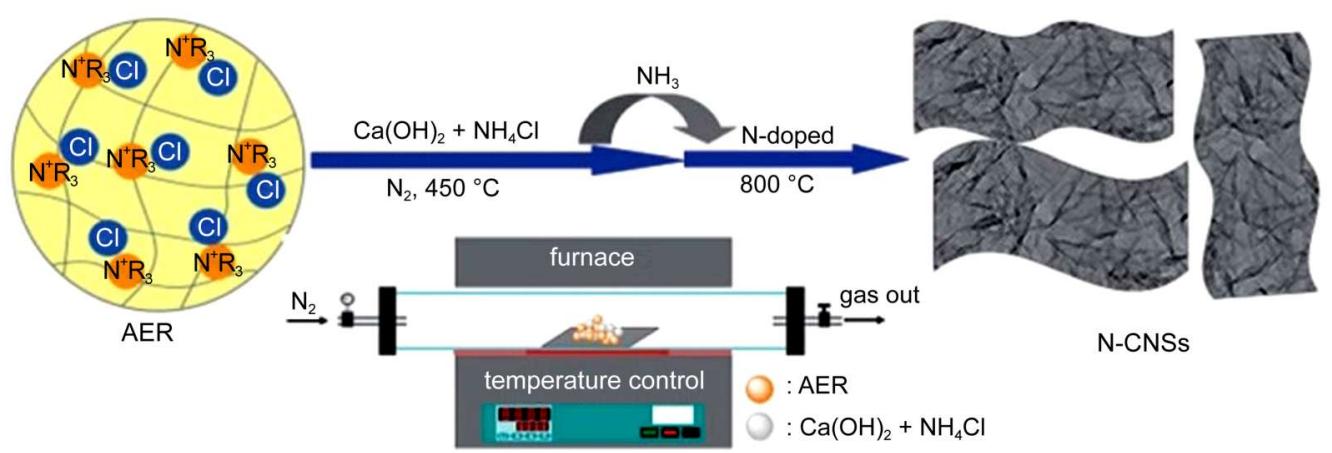

Fig.5 Schematic of the preparation process of $\mathrm{N}-\mathrm{CNSs}^{58}$

and centered in the range of $2-10 \mathrm{~nm}$, corresponding to the existence of abundant mesopores.

The self-assembled organic nanosheets or biomass sources can be the carbon precursor for direct carbonization synthesis of mesoporous carbon nanosheets. Different from the templating method, the self-assembled sheet-like carbon precursor is often prepared through polymerization of monomers with a certain direction without the assistance of a template, which also simplified the preparation procedure, i.e. removal of templates can be omitted. However, only certain types of carbon naosheets can be prepared by this method due to the limitation of precursors. Yuan et al. ${ }^{60}$ prepared mesoporous N-containing carbon nanosheets $(\mathrm{N}-$ $\mathrm{CNSs}$ ) by using polyaniline nanosheets (NSs) as a carbon precursor. The polyaniline NSs were fabricated through self-assembly by an oxidative polymerization of aniline monomer with potassium persulfate (PPS) under mild hydrothermal condition. After direct carbonization of polyaniline NSs, N-CNSs can be obtained with a well-developed mesoporous architecture $\left(0.32 \mathrm{~cm}^{3} \cdot \mathrm{g}^{-1}\right)$, $5.9 \%(w) \mathrm{N}$ species, a specific surface area of $352 \mathrm{~m}^{2} \cdot \mathrm{g}^{-1}$, and average pore size of $5.2 \mathrm{~nm}$.

\subsubsection{Other porous carbon structures}

By a one-step chemical activation method, highly porous, oriented, and interlinked carbon nanosheets were prepared using hydrothermally polymerized glucose spheres (pGSs) as precursor $^{61}$. The unique carbon nanosheets were directly produced from pGSs after one-step activation by $\mathrm{KOH}$, which displayed dramatic morphological change compared with the traditional two-step process (pre-carbonization followed by activation, yielding microporous carbon spheres). The carbon nanosheets had a surface area of $2633 \mathrm{~m}^{2} \cdot \mathrm{g}^{-1}$ and a pore volume of $1.86 \mathrm{~cm}^{3} \cdot \mathrm{g}^{-1}$. During the one-step activation, the melt of potassium species directed the formation of oriented carbon nanosheets; the oxygen constituents in the pGSs are critical for the morphological evolution from sphere to sheet structure.

Similarly, a 3D interconnected frameworks composed of sandwiched graphene/porous carbon layers with $20 \mathrm{~nm}$ thickness was synthesized by using a facile one-step pyrolysis of the mixture of graphene oxide (GO)/polyaniline (PANI) hybrid and $\mathrm{KOH}^{62}$. The obtained porous carbon material exhibited a high specific surface area $\left(2927 \mathrm{~m}^{2} \cdot \mathrm{g}^{-1}\right)$, hierarchical interconnected pores, moderate pore volume $\left(1.78 \mathrm{~cm}^{3} \cdot \mathrm{g}^{-1}\right)$, short ion diffusion paths, and a nitrogen level of $6 \%(a)$. To be noted, the hierarchically connected pores (micro-, meso- and macropores) provide unimpeded channels for fast diffusion of electrolyte ions and result in an enhanced charge storage and high rate capability.

The biomass sources with nanosheet structures can also be the carbon precursors. Jin and co-workers ${ }^{63}$ has developed hierarchically porous carbon nanosheets (HP-CNSs) using exfoliated waste coffee grounds by in-situ carbonization and activation processes using $\mathrm{KOH}$. Despite the simple synthesis process, the HP-CNSs had a high aspect ratio nanostructure ( $20 \mathrm{~nm}$ thickness to several micrometers in lateral size), a specific surface area of $1945.7 \mathrm{~m}^{2} \cdot \mathrm{g}^{-1}$, numerous heteroatoms, and good electrical transport properties, as well as hierarchically porous characteristics $(0.5-10.0 \mathrm{~nm}$ in pore size).

\subsection{CVD method}

Chemical vapor deposition (CVD) method has been widely used in producing $2 \mathrm{D}$ carbon materials. In this process, a gaseous carbon precursor is subject to high-temperature treatment, which induces decomposition, radical formation, and aggregation of the precursor molecules. The growth of these agglomerates through continued deposition and decomposition of the carbon precursor ultimately leads to the formation of $2 \mathrm{D}$ carbon materials. The gaseous precursor can be formed by vaporization, sublimation, or atomization of a solid or liquid source. There are numerous references for graphene or graphene oxide with perfect graphitic crystallinity using CVD method ${ }^{64-66}$. However, there are limited amounts of reports for carbon nanosheets using CVD method, and the porosity has not been fully discussed. It has been proved that porous carbon nanosheets derived from CVD method show advantages of a high degree of graphitization, a regular arrangement, and controllable thickness.

Wang et al. ${ }^{67}$ has reported a free-standing sheet-like carbon nanostructure by inductively coupled radio-frequency plasma enhanced chemical vapor deposition (PECVD) without catalyst or special surface pretreatment. Such nanosheets with thickness of ca $1 \mathrm{~nm}$ were obtained without catalyst over a wide range of deposition conditions and on a variety of substrates, including metals, semiconductors and insulators. Such carbon sheets fabricated by the direct CVD and PECVD methods, seem attractive to researchers of fundamental materials chemistry, nanoscience and technology because of their potential applications in 
nanodevices, capacitors, and chemical and bio-sensors.

Mesoporous carbon sponge consisting mostly of single-layer graphene walls has been prepared by CVD method using $\mathrm{Al}_{2} \mathrm{O}_{3}-\mathrm{NP}$ as a nanosized substrate, defined as graphene mesosponge $(\mathrm{GMS})^{68}$. After the CVD process, the color of the sample turned black with the quartz tube remaining transparent, indicating that carbon deposition only occurred on the surface of $\mathrm{Al}_{2} \mathrm{O}_{3}-\mathrm{NP}$ due to its catalysis. Therefore, the entire surface of $\mathrm{Al}_{2} \mathrm{O}_{3}-\mathrm{NP}$ can be covered by a quite thin carbon layer. As the $\mathrm{Al}_{2} \mathrm{O}_{3}$ - NPs are not sintered, the shape of the resulting carbon coated $\mathrm{Al}_{2} \mathrm{O}_{3}-\mathrm{NP}\left(\mathrm{Al}_{2} \mathrm{O}_{3}-\right.$ $\mathrm{NP} / \mathrm{C}$ ) is similar to that of $\mathrm{Al}_{2} \mathrm{O}_{3}$-NP (Fig.6). The mean pore size is $5.8 \mathrm{~nm}$ for the obtained GMS.

$\mathrm{Xu}$ et al.$^{69}$ prepared small, thin carbon nanosheets (thickness of 2-5 nm) via CVD method using $\mathrm{CaO}$ as template and toluene as carbon precursor. During the CVD process, toluene is pyrolyzed to generate carbon atoms and then deposit on the nano- $\mathrm{CaO}$ particles. After template removal, the carbon nanosheets are obtained with a tunable thickness by changing deposition time.

CNSs synthesized by the CVD method exhibit high-quality, large-area features. However, it is very difficult to achieve precise control of the properties of the resulting carbon materials in terms of surface area, pore size, and surface functionality ${ }^{70}$.

\subsection{Hydrothermal method}

Hydrothermal process is widely employed to fabricate 2D carbon-based porous materials from diverse carbon precursors, especially biomass resources at relatively mild conditions. The size, shape distribution, and crystallinity of carbon nanostructures can be altered by controlling experimental conditions, including reaction temperature, reaction time, surfactant type, and precursor types, etc.

Wang et al. ${ }^{71}$ reported a combined hydrothermal and activation processes with $\mathrm{KOH}$ that uses natural fibers (hemp bast fiber) as the precursor to achieve graphene-like carbon nanosheets. The obtained carbon nanosheets showed unique interconnected partially graphitic structure $(10-30 \mathrm{~nm}$ in thickness $)$ with high specific surface area (up to $2287 \mathrm{~m}^{2} \cdot \mathrm{g}^{-1}$ ) and large volume fraction of mesoporosity (up to $58 \%$ ). The macroporous voids with diameters of $1-2 \mu \mathrm{m}$ serve as ion buffering reservoirs. The low thickness of the carbon nanosheets $(10-30 \mathrm{~nm})$ ensures nanoscale distances $(5-15 \mathrm{~nm})$ for ion diffusion. The high total content of mesopores facilitates the accessibility of the electrolyte ions to the electrode surface and allows for fast ion transport.

2D mesoporous carbon nanosheets (MCNSs) were prepared with approximately $40 \mathrm{~nm}$ thickness and $10 \mathrm{~mm}$ width $^{72}$. Large numbers of mesopores with an average size of $9 \mathrm{~nm}$ are distributed in a disorder manner throughout the nanosheets. Such 2D carbon nanosheets with mesopores can enhance the rate performances and simultaneously maintain its high capacities and robust cycle life in lithium ion battery. The MCNSs were prepared by hydrothermal pretreatment of sodium and ethylene glycol in a closed Teflon reactor followed by a rapid pyrolysis procedure. During the hydrothermal process, the ethylene glycol solution became increasingly saturated with the metal alkoxide as it forms. And as a result of the autogenerated pressure, the excess free ethylene glycol was encapsulated into the solid metal alkoxide forming a clathrate-like structure, which can be used as ignition points in the following pyrolysis process. Therefore, nucleation of 2D MCNSs occurred around the regions rich in ethylene glycol. It was called a "popcorn effect" ${ }^{73}$. Experiments performed on non-clathrated, crystalline sodium ethoxide were not found to result in the formation of carbon nanosheets, indicating that the hydrothermal conditions are essential to produce the proper precursors.

\subsection{Controlled assembly of 2D carbon-based materials}

Many other 2D compounds beyond carbon are also important owing to their unique catalytic or electronic properties, such as transition metal oxides (TMOs), layered double hydroxides $(\mathrm{LDH})$, boron nitride $(\mathrm{BN})$, transition metal dichalcogenides (TMDs), etc. The assembly of 2D carbon nanostructures and these $\mathrm{O}, \mathrm{S}$, or $\mathrm{N}$ containing nanosheets can create novel properties distinct from the parent materials. In this section, the synthesis methods of the carbon-based layered hybrids are summarized and classified according to the fabrication methods. Generally, the assembly methods can be divided into three types: layer-by-layer assembly, electrostatic hetero-assembly, and epitaxial growth.

\subsubsection{Layer-by-layer (LBL) assembly}

Layer-by-layer (LBL) assembly technique has been a premier method for the preparation of nanoscale films with tunable
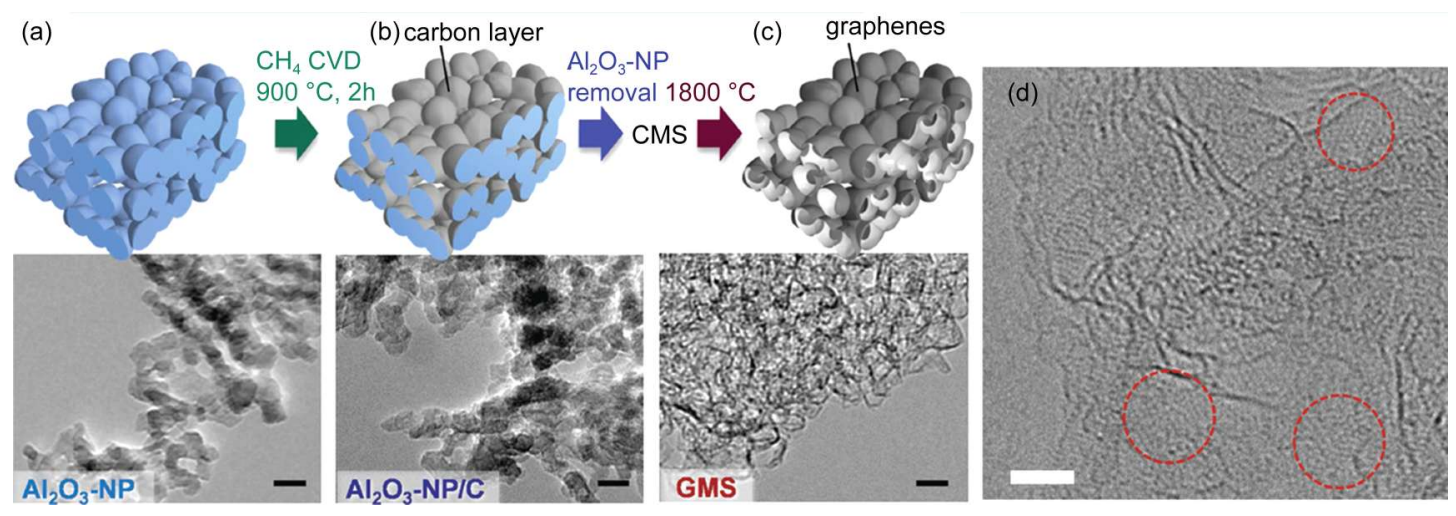

Fig.6 (a-c) A schematic of the synthesis of GMS with TEM images at each step; (d) atomic-resolution TEM image of GMS ${ }^{68}$ The scale bars are $10 \mathrm{~nm}$ in $(\mathrm{a}-\mathrm{c})$ and $2 \mathrm{~nm}$ in $(\mathrm{d})$. 
composition, thickness, and function groups ${ }^{74}$. Typically, the LBL process started from the adsorption of oppositely charged precursors onto the substrate, which therefore reversed the surface charge. Further layers can be deposited by alternating the adsorption species with opposite charge until achieving the desired thickness.

A wide variety of oxides and hydroxide are composed of primary units with layered structure, including hydrotalcites, $\delta$ $\mathrm{MnO}_{2}, \mathrm{FeOOH}$, etc. ${ }^{5,75}$. Among the $2 \mathrm{D}$ oxides/hydroxides family, layered double hydroxide (LDH) is one class of anionic materials based on the brucite-like layered structures ${ }^{7}$. With the development of synthetic methods and anion-exchange procedure, the LDH composites have been enriched during the last decade, which can be further assembled with carbon nanosheets to obtain novel 2D materials ${ }^{8}$. Chen et $a .^{76}$ synthesized electrically conductive poly (vinyl alcohol) (PVA) hybrid films utilizing the hydrogen-bonding layer-by-layer self-assembly method. Before the assembly, graphene oxides and single-layer LDH nanosheets were exfoliated from natural graphite oxide powders and crystallized $\mathrm{Co}-\mathrm{Al}-\mathrm{NO}_{3}$ $\mathrm{LDH}$, respectively. Utilizing the hydrogen bonding interaction of PVA/GO and PVA/LDH, multilayer hybrid with highly oriented GO and LDH were fabricated. In this process, PVA acted as a bridge to connect GO and LDH.

Dong et $a .^{77}$ developed a simpler way for fabricating LDH-GO hybrid using layer-by-layer assembly. Poly(diallyldimethylammonium chloride) coated ITO was employed as a substrate, which was first immersed into the Co-Al LDH dispersion for deposition following washing and drying processes. Afterwards, the substrate was immersed into GO suspension for a second layer deposition. The cycle was repeated until a desired amount of bilayers obtained. This method can be extended to the preparation of flexible electrode using PET as a substrate.

\subsubsection{Electrostatic hetero-assembly}

Different from graphene with a relatively weak interlayer interaction, the oxides/dichalcogenides layered materials have a high layer charge density that generates nanosheets with positive or negative charges ${ }^{5}$. Such unique property has been used for the assembly of 2D hybrids using electrostatic force. Generally, the electrostatic fabrication process is based on the exfoliation or delamination of the bulk materials to get sheet-like debris with opposite charges.

For example, LDH nanosheets (LDH-NS) with positive charge can be obtained via delamination, while GO nanosheets are negatively charged in basic solutions. Thus the electrostatic interaction between GO and LDH-NS created a self-assembly of two sheets. Wang et al. ${ }^{78}$ reported the fabrication of Co-Al LDH-NS with GO using electrostatic assembly. The Co-Al LDH-NS was delaminated in formamide and GO dispersed in water. After mixing the two solutions together, the assembly process occurred automatically. Similarly, the assembled Ni-Al LDH and GO nanosheets can also be prepared using the same method ${ }^{79}$.

To simplify the synthesis procedure, the delamination process of LDH can be bypassed through modification of the LDH pre- cursors. Long et al. ${ }^{80}$ employed Cl-exchanged Ni-Fe LDH and GO as precursors. The negatively charged GO can be assembled directly into the $\mathrm{LDH}$ interlayer as anion. Latorre-Sanchez et al. ${ }^{81}$ synthesized a hybrid containing graphene and $\mathrm{Ni}_{6} \mathrm{MnO}_{8}$ through an electrostatic assembly of Ni-Mn LDH and GO following a calcination process. As a Ni-Mn LDH suspension can be obtained during the deposition process in methanol and showed good exfoliation property, a delamination step was unnecessary. The fabrication of $\mathrm{Mg}-\mathrm{Al} \mathrm{LDH} / \mathrm{GO}$ hybrid aerogel was assisted by ultrasonic treatment after dispersion LDH into GO suspension ${ }^{82}$. Herein, GO played an ion-exchange role and inserted into the interlayer of $\mathrm{Mg}-\mathrm{Al} \mathrm{LDH}$, and $\mathrm{LDH}$ acted as cross-linking agent for the fabrication of such aerogel.

In general, the surface charge of GO is determined by the dispersed solution. For example, the DMF-exfoliated graphene is electropositive, so that it can interact with negatively charged nanosheets. Xie's group ${ }^{83}$ reported $\delta-\mathrm{MnO}_{2} /$ graphene hybrid for supercapacitor using chemically integration of electropositive $\delta$ $\mathrm{MnO}_{2}$ nanosheets on graphene due to the strong electrostatic interaction. This method can be extended to prepare other $2 \mathrm{D}$ hybrid materials, e.g., the fabrication of carbon nitride $\left(\mathrm{C}_{3} \mathrm{~N}_{4}\right)$ and $\mathrm{LDH}$ using electrostatic interactions ${ }^{84}$.

Furthermore, dichalcogenide and carbon nanosheets can be used for the fabrication of hybrid materials. Zhou et al.$^{85}$ reported the synthesis of $\mathrm{MoS}_{2}-\mathrm{RGO}$ hybrids with nanosheet-nanosheet structure via a lithiation-assisted exfoliation process following a hydrazine monohydrate vapor reduction technique. The $\mathrm{MoS}_{2}$ was firstly exfoliated into nanosheets by electrochemical lithiation approach, and then mixed with GO following a hydrazine reduction process to get $\mathrm{MoS}_{2}-\mathrm{RGO}^{86}$. Due to the existence of chemical bond formed between $\mathrm{MoS}_{2}$ nanosheets and graphene oxides, the agglomeration of $\mathrm{MoS}_{2}$ nanosheets can be effectively restricted and the growth of Mo nanoparticles during lithiation was limited. Similarly, Liu et al ${ }^{87}$ synthesized $\mathrm{MoS}_{2} /$ graphene nanocomposite using commercial bulk $\mathrm{MoS}_{2}$ as precursor. The preparation process included the hydrolysis of lithiated $\mathrm{MoS}_{2}$ with the assistant of untrasonication and the fabrication of $\mathrm{MoS}_{2}$ and GO through electrostatic interactions. Peng et al ${ }^{88}$ developed one-pot synthesis of $\mathrm{MoS}_{2} / \mathrm{GO}$ hybrid in aqueous solution. It was found that the size of GO plays an important role in tuning the structure of $\mathrm{MoS}_{2} / \mathrm{GO}$.

\subsubsection{Epitaxial growth/deposition}

Another bottom-up method for fabricating 2D carbon-based materials is the epitaxial growth of one composite on the "nanosheet substrates". The key point is how to control the nanosheet morphology and thickness of the grown layer. For example, GO nanosheets possess negative charge in basic solution, the in-situ growth of positive charged LDH nanosheets can be achieved using GO as a support. Meanwhile, the LDH nanosheets can be highly dispersed on GO without stacking together. GarciaGallastegui et al.$^{89}$ reported the in-situ deposition of $\mathrm{Mg}-\mathrm{Al} \mathrm{LDH}$ onto GO nanosheets. Before the deposition process, GO was firstly dispersed into a basic solution containing $\mathrm{NaOH}$ and 
$\mathrm{Na}_{2} \mathrm{CO}_{3}$. The mixed salt solution of $\mathrm{Mg}\left(\mathrm{NO}_{3}\right)_{2}$ and $\mathrm{Al}\left(\mathrm{NO}_{3}\right)_{3}$ were then added. The as-obtained suspension was then aged at $333 \mathrm{~K}$ for $12 \mathrm{~h}$, washed and dried to get the $\mathrm{LDH} / \mathrm{GO}$ hybrid. Gao et al. ${ }^{90}$ employed glucose reduced $\mathrm{GO}$ as a substrate for $\mathrm{Ni}-\mathrm{Al} \mathrm{LDH}$ growth. The existence of $\mathrm{Ni}-\mathrm{Al} \mathrm{LDH}$ efficiently separated the carbon nanosheets and enhanced the electrochemical properties.

Solvents also influenced the structure of the resulted oxides grown on graphene nanosheets. Kan and Wang reported the deposition of $\mathrm{Fe}_{2} \mathrm{O}_{3}$ on graphene oxide employing different solvents $^{91}$. They discovered that sheet-on-sheet structure can be obtained when the preparation process was carried out in isopropanol. In contrast, particle-on-sheet structure was formed when using water instead of isopropanol as the solvent.

Layered transition metal dichalcogenides, such as $\mathrm{VS}_{2}{ }^{92,93}$, $\mathrm{WS}_{2}{ }^{94}$, and $\mathrm{MoS}_{2}{ }^{95}$, have attracted much attention due to their 2D structure analogous to graphene and applications in electrocatalysis and energy storage ${ }^{96-98}$. Many exfoliation methods including mechanical ${ }^{99}$ or chemical exfoliation ${ }^{100}$, chemical vapor deposi$\operatorname{tion}^{101}$, and solution synthesis ${ }^{102}$, have been established. However, this type of material tends to form fullerene-like nanoparticles or nanotube structures instead of thin layer during processing. To overcome this tendency, the deposition of layered dichalcogenides on graphene oxides was discovered as an effective way to inhibit their growth into 3D structure ${ }^{103-105}$. The most studied method is insitu growth of dichalcogenide nanoflakes over GO or RGO for the preparation of carbon-dichalcogenide 2D hybrids. Generally, the GO sheets are used as the substrate for a deposition of dichalcogenide precursors, and followed by a thermal treatment, if necessary. Dai's group ${ }^{104}$ synthesized a $\mathrm{MoS}_{2} / \mathrm{RGO}$ hybrid in DMF solution employing a selective solvothermal method. They used a single compound $\left(\mathrm{NH}_{4}\right)_{2} \mathrm{MoS}_{4}$ as the source for Mo and $\mathrm{S}$. The as-obtained $\mathrm{MoS}_{2} / \mathrm{RGO}$ hybrid material possessed nanoscopic fewlayer $\mathrm{MoS}_{2}$ structures with large amount of exposed edges stacked onto graphene, which exhibited superior electrocatalytic activity in the hydrogen evolution reaction (HER) compared to other $\mathrm{MoS}_{2}$ catalysts. Chang et al. ${ }^{103}$ developed a hydrothermal route for preparing $\mathrm{MoS}_{2} / \mathrm{RGO}$ hybrid using $\mathrm{Na}_{2} \mathrm{MoO}_{4}$ and $\mathrm{NH}_{2} \mathrm{CSNH}_{2}$ as precursors, which showed up to $1300 \mathrm{mAh} \cdot \mathrm{g}^{-1}$ capacity as an anode material for Li-ion battery. Moreover, microwave-assisted synthesis approach was developed on the basis of nonhydrolytic sol-gel method using butyl mercaptan as $\mathrm{S}$ source and $\mathrm{MoCl}_{5}$ as Mo source ${ }^{106}$.

\section{Applications of 2D carbon-based materials}

Due to their ultrahigh surface-to-volume ratio, unique chemical and physical properties, and tunable composition, 2D carbonbased materials have been widely studied and utilized in the fields of catalysis, energy storage, water purification, electronic and photonic industries. These aspects have been summarized from different viewpoints ${ }^{17,107}$. In this section, we will focus on the applications in adsorption/separation and heterogeneous catalysis (including electronic and photonic catalysis). Others, such as energy storage, biology, and environment protection will also be briefly touched.

\subsection{Adsorption and separation}

Conventional porous adsorbents always have a large bulk size in all dimensions, and it therefore takes a long time for the adsorbate molecules to transfer into and out of the inner microporous network. This leads to a lack of adsorbates in the inner pores and low utilization of the overall surfaces and pores. In this case, 2D materials with large surface-to-volume ratio and nanosized thickness can efficiently promote the adsorbate diffusion rate, decrease the adsorption resistance, and improve the utilization of the overall surfaces and pores ${ }^{108}$.

Tuning porous structure and functional groups are two main strategies to improve $\mathrm{CO}_{2}$ adsorption. Moreover, the assembly of CNSs can produce macroscopic structures, which further improved the diffusion rate and mechanical property of the final material. Lu's group has designed a series of $2 \mathrm{D}$ porous carbon sheets for $\mathrm{CO}_{2}$ separation ${ }^{14,32,108,109}$. The systematic studies indicate that the porous carbon nanosheets show impressive $\mathrm{CO}_{2}$ adsorption capacity under equilibrium and more better separation ability of $\mathrm{CO}_{2}$ from $\mathrm{N}_{2}$ under dynamic conditions than the counterpart bulk or spherical materials (Fig.7) ${ }^{14}$. The hierarchically interconnected porous structure (including macropores and mesopores) could greatly enhance the diffusion of adsorption gas molecule and maintain an excellent mechanical strength. The highest $\mathrm{CO}_{2}$ adsorption capacities can reach 5.67 and $3.54 \mathrm{CO}_{2}$ molecules per $\mathrm{nm}^{3}$ pore volume and per $\mathrm{nm}^{2}$ surface area at 298 $\mathrm{K}$ and $0.1 \mathrm{MPa}$. Additionally, the monolithic materials assembled from nanosheets have a mechanical strength of up to 28.9 $\mathrm{MPa}$ (the highest reported for the analogues).

Beyond the construction of porous structure, the incorporation of nitrogen groups into the CNS results in improved adsorption/ desorption of $\mathrm{CO}_{2}$. Shen et al. ${ }^{110}$ developed nitrogen-doped porous CNSs with a thickness of $20-40 \mathrm{~nm}\left(S_{\mathrm{BET}}=1854 \mathrm{~m}^{2} \cdot \mathrm{g}^{-1}\right.$, pore volume $=0.82 \mathrm{~cm}^{3} \cdot \mathrm{g}^{-1}$ ), which displayed $\mathrm{CO}_{2}$ adsorption of 5.8 $\mathrm{mmol} \cdot \mathrm{g}^{-1}$ at $298 \mathrm{~K}$. Chen's group developed a $2 \mathrm{D}$ carbonaceous polymer nanosheets by polymerizing aromatic nitrile monomers in molten zinc chloride at $400-500{ }^{\circ} \mathrm{C}^{111}$. As-obtained nanosheets possess tunable thicknesses of 3-20 nm, well-defined microporosity, a high surface area $\left(\sim 537 \mathrm{~m}^{2} \cdot \mathrm{g}^{-1}\right)$, and a large micropore volume $\left(\sim 0.45 \mathrm{~cm}^{3} \cdot \mathrm{g}^{-1}\right)$. The $\mathrm{CO}_{2}$ sorption capability reached $8.14 \%(w)$ at $298 \mathrm{~K}$ and $0.1 \mathrm{MPa}$, and the $\mathrm{CO}_{2}$ selectivity was relatively high toward $\mathrm{N}_{2}$ (25.6).

Moreover, the 2D carbon-inorganic composite materials (e.g. LDH materials ${ }^{86,112}$ ) showed enhanced $\mathrm{CO}_{2}$ adsorption. The absolute capacity of the combined material increased $62 \%$ compared with LDH using only 7\% (w) graphene oxide (GO) as a support because of its 2D structure with large amount of basic sites, which showed excellent affinity to the acid $\mathrm{CO}_{2}$ molecule ${ }^{86}$. Additionally, 2D carbon materials are suitable for physical adsorption of $\mathrm{H}_{2}$, based on first principles investigation ${ }^{113}$. It has been proven that the adsorption energy on graphynes is larger than zeolite and MOFs and the $\mathrm{H}_{2}$ equilibrium distance is closer to the carbon plane, which is beneficial for both $\mathrm{H}_{2}$ intercalation and out-of-plane 

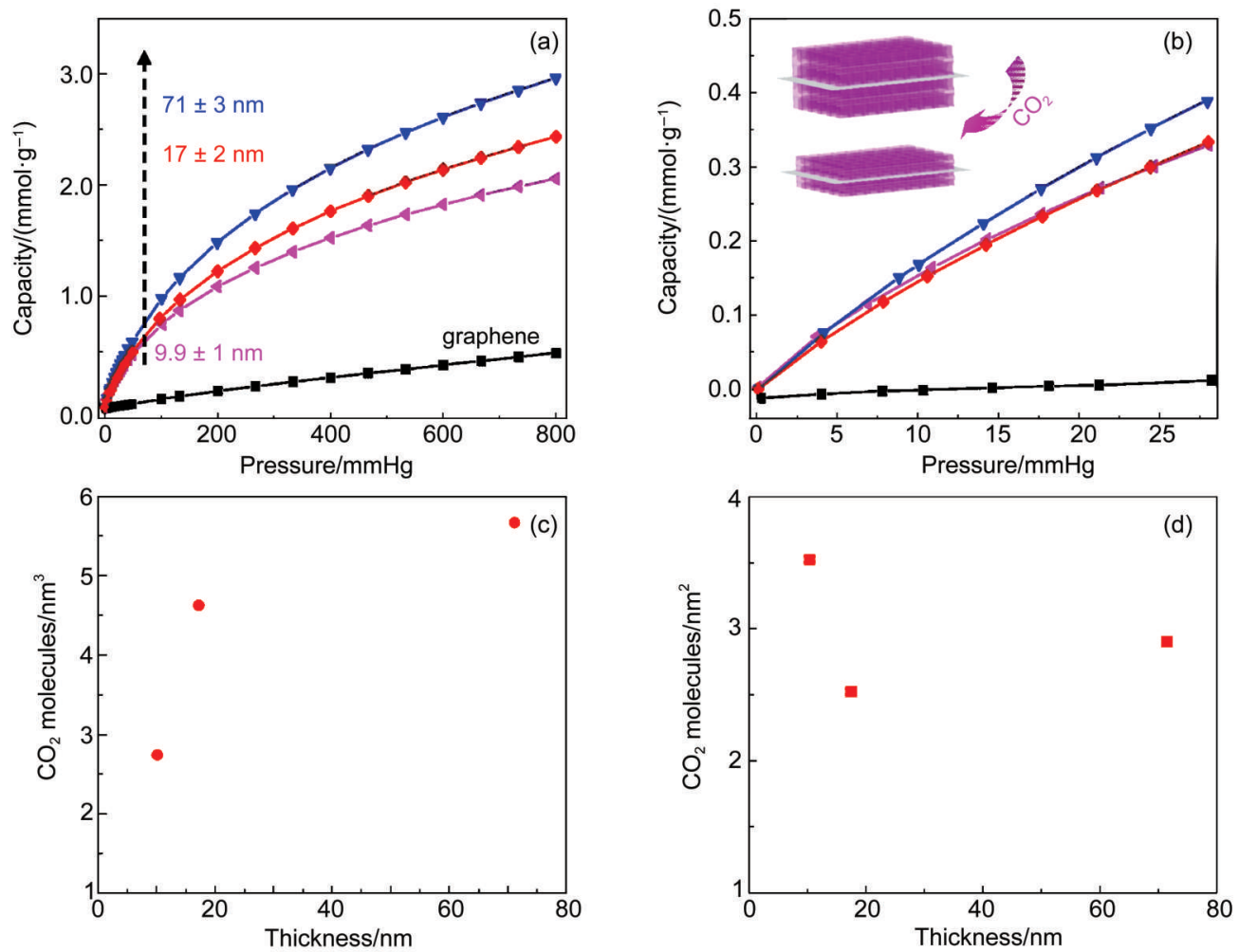

Fig.7 (a, b) $\mathrm{CO}_{2}$ adsorption isotherms of the porous carbon nanosheets ( $\mathrm{PCNs}$ ) for high and low $\mathrm{CO}_{2}$ partial pressures at $298 \mathrm{~K}$, where the solid line represents a Toth model fit to the $\mathrm{CO}_{2}$ isotherms; (c) number of $\mathrm{CO}_{2}$ molecules adsorbed per $\mathrm{nm}^{3}$ pore volume and (d) per $\mathrm{nm}_{2}$ surface area for $\mathrm{PCNs}$ with different thicknesses ${ }^{14}$

$1 \mathrm{mmHg}=133.3 \mathrm{~Pa}$

diffusion. Zeolite membranes have been employed as precursors to prepare $2 \mathrm{D}$ carbon materials for gas separation by Zhong and coworkers $^{114}$. They prepared carbon composite membrane by direct carbonization of zeolitic imidazolate framework (ZIF-L), which showed high $\mathrm{H}_{2} / \mathrm{CO}_{2}$ selectivity with a very high $\mathrm{H}_{2}$ permanence $\left(\sim 3.5 \times 10^{-6} \mathrm{~mol} \cdot \mathrm{m}^{-2} \cdot \mathrm{s}^{-1} \cdot \mathrm{Pa}^{-1}\right)^{114}$. By creating such precisely controlled materials with short diffusion paths and high microporosity, instead of larger pores (little contribution to gas sorption capacity), the $2 \mathrm{D}$ porous carbon materials can greatly accelerate adsorption kinetics, increasing the utilization degree of the overall porosity and surface area.

Along with its excellent performance in gas adsorption, 2D carbon-based materials are also considered as good adsorbents for removal of heavy metal ions, organic dyes from water. For example, the fabricated porous carbon nanosheets with $\mathrm{Fe} / \mathrm{Fe}_{3} \mathrm{C}$ nanoparticles exhibited excellent adsorption property for methylene blue (MB), methyl orange (MO) and crystal violet (CV). The maximum adsorption capabilities for $\mathrm{MB}, \mathrm{MO}$, and $\mathrm{CV}$ reached $1615.9,1062.4$, and $1728.3 \mathrm{mg} \cdot \mathrm{g}^{-1}$, respectively ${ }^{38}$. Moreover, the possibility of magnetic separation also facilitated its application in wastewater treatment on a large scale. This multifunctional material can potentially be used as a super adsorbent to efficiently remove pollutants from wastewater. Notably, macroscopic graphene-based assemblies and architectures, e.g., graphene hydrogels and aerogels ${ }^{115}$, and graphene sponges ${ }^{116,117}$ and foams ${ }^{118}$ have shown promising potential as removal candidates (heavy metals, oils, and dyes) with low density, high adsorption capacity, high selectivity, good recyclability, and environmental compatibility for water treatment, owing to their combined merits of large surface area, high chemical stability, and facile functionalization. Despite the above great advantages, direct experiment data and theoretical calculations on the relevance of properties and structures are quite limited. Lu's group ${ }^{108}$ designed and synthesized two model microporous carbon materials, i.e., carbon nanosheets $(\mathrm{MCN})$ and carbon spheres (MCS) having nearly same composition, surface chemistry, and specific surface area, known morphology, but distinguishable diffusion paths (Fig.8). The results indicate that sheet structures are ideal for quick response applications in gas and liquid phase environments.

Moreover, the assembled graphene-inorganic 2D structures performed an enhanced adsorption capability, which guarantee the exposure of the active sites in aqueous solution and overcome the utilization restrictions of neat GO aerogels. Yu's group ${ }^{119}$ has synthesized a kind of $\mathrm{FeOOH} /$ graphene hydrogel by the metal ion induced assembly process under mild conditions, which showed a high adsorption capacity to nonpolar organic solvents and oils, with a maximum uptake capacity of 27 times its own weight and good recyclability. Additionally, it exhibited an outstanding capability for the removal of heavy metal ions, such as those presenting 139.2 and $373.8 \mathrm{mg} \cdot \mathrm{g}^{-1}$ adsorption capacities for $\mathrm{Cr}(\mathrm{VI})$ 

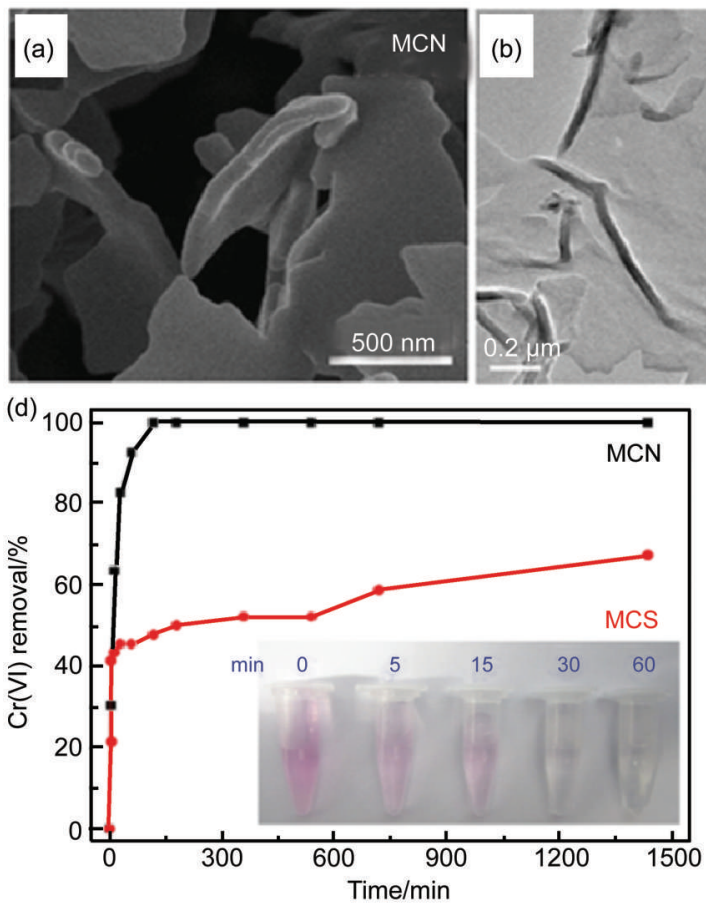
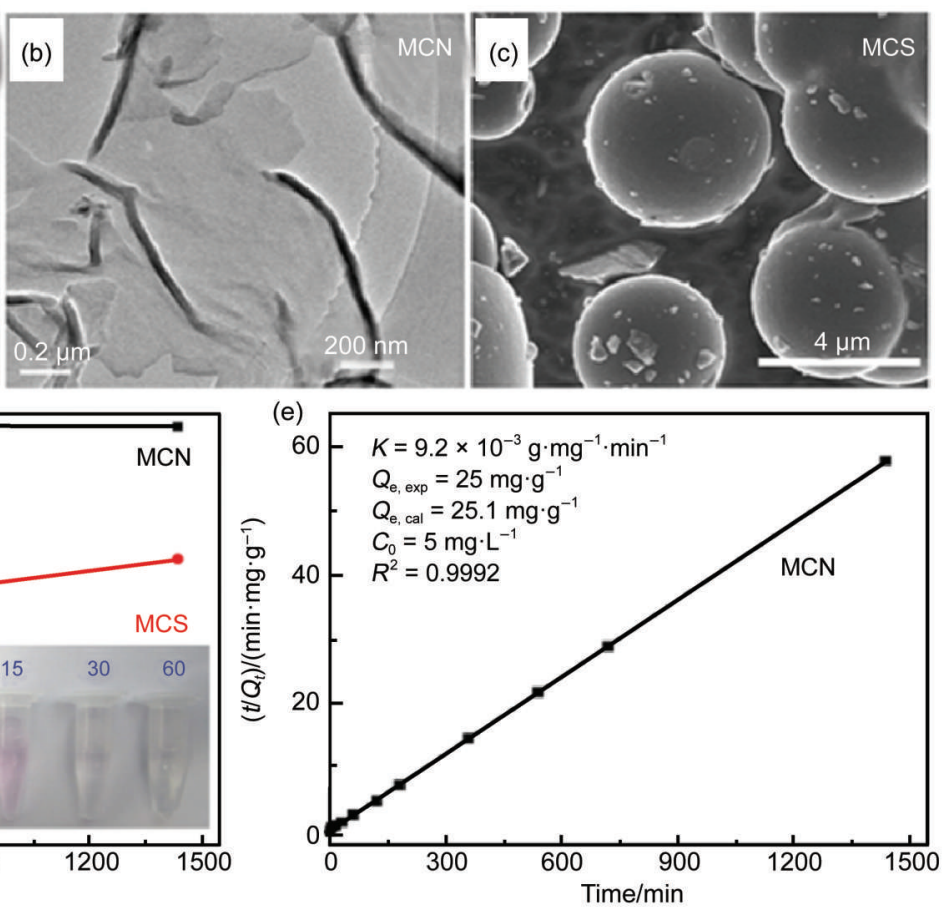

Fig.8 (a-c) SEM and TEM images of MCN and MCS; (d, e) adsorption of Cr(VI) on MCN and MCS ${ }^{108}$

and $\mathrm{Pb}(\mathrm{II})$, respectively. The above results strongly confirm that porous carbon sheets exhibit improved kinetics in gas phase separation, liquid phase enrichment, and energy storage devices, due to their shorter diffusion paths and larger exposed geometrical area derived from the $2 \mathrm{D}$ structure.

\subsection{Heterogeneous catalysis}

In heterogeneous catalysis, most of the reactions occur on the surface of catalysts, which means that mass and heat transfer are the most important factors beyond the catalytic reaction itself. The large surface-to-volume structure of 2D materials is beneficial for mass and heat transfer, which also provide more active sites available on the surface. Therefore, more attention has been paid for 2D materials in heterogeneous catalysis. Traditionally, carbon materials are often employed as inert support for loading active components. However, due to its good conductivity and tunable surface defects, carbon materials showed unique catalytic activity in electrocatalysis as non-metal catalysts. Also, with the development of the graphene-like $\mathrm{C}_{3} \mathrm{~N}_{4}$ material, explosive investigations have been carried out for photocatalysis processes. Notably, the applications of few layered graphene or graphene oxide have been documented in previous reviews, both as carbocatalysts or support for loading active components ${ }^{16,120-122}$. However, the applications of 2D carbon-based materials, including the assembled composites, have not been systematically discussed. In this part, we will focus on the most recent applications of 2D materials in heterogeneous catalysis based on the materials mentioned in Section 2, especially elecrocatalysis and photocatalysis.

\subsubsection{Electrocatalysis}

In electronic catalysis processes, the activity is usually originated from metal particles, metal oxides, dichalcogenides, or other heteroatoms instead of carbon. However, the low electric conductivity limited their applications. The strategy to solve the problem is to construct hybrid materials consisted of active components and conducting graphitic carbon. Based on the assembled materials, their electrocatalysis performances will be discussed hereafter.

Development of electrocatalysts for the oxygen evolution reaction (OER) is critical to energy conversion and storage processes. Among various catalysts, $\mathrm{IrO}_{2}$ is considered as the most efficient for OER. However, the high cost and element scarcity hindered its industrial applications. Therefore, the development of non-noble-metal catalytic systems is desirable. The first row transition metal based materials are considered as promising alternatives. Long et al..$^{80}$ reported the fabrication of FeNi layered double oxide-GO hybrid as an active catalyst for OER. This nonnoble-metal-based electrocatalyst exhibited high activity (TOF is $1 \mathrm{~s}^{-1}$ at $0.3 \mathrm{~V}$ ), which can be attributed to the synergy effect of the catalytic active FeNi oxides and the enhanced electron transport arising from the graphene nanosheets. Lou's group synthesized carbon coated nickel phosphide with porous nanoplate structure (Fig.9) ${ }^{123}$. Compared with $\mathrm{NiO}$ and $\mathrm{Ni}(\mathrm{OH})_{2}$, as-prepared nickel phosphides manifest superior electrocatalytic activity for OER due to their structural merits and the in-situ formed catalytically active oxidized nickel species.

Hydrogen evolution reaction (HER) is another important reaction for clean energy and environment protection. Transition metal dichalcogenides (e.g., $\mathrm{MoS}_{2}{ }^{124}, \mathrm{WS}_{2}{ }^{94}$ ) are discovered as active electrocatalysts to replace noble metal Pt for HER. The computational and experimental results have confirmed that the HER activity stemmed from the sulfur edges of $\mathrm{MoS}_{2}$ plates. The 

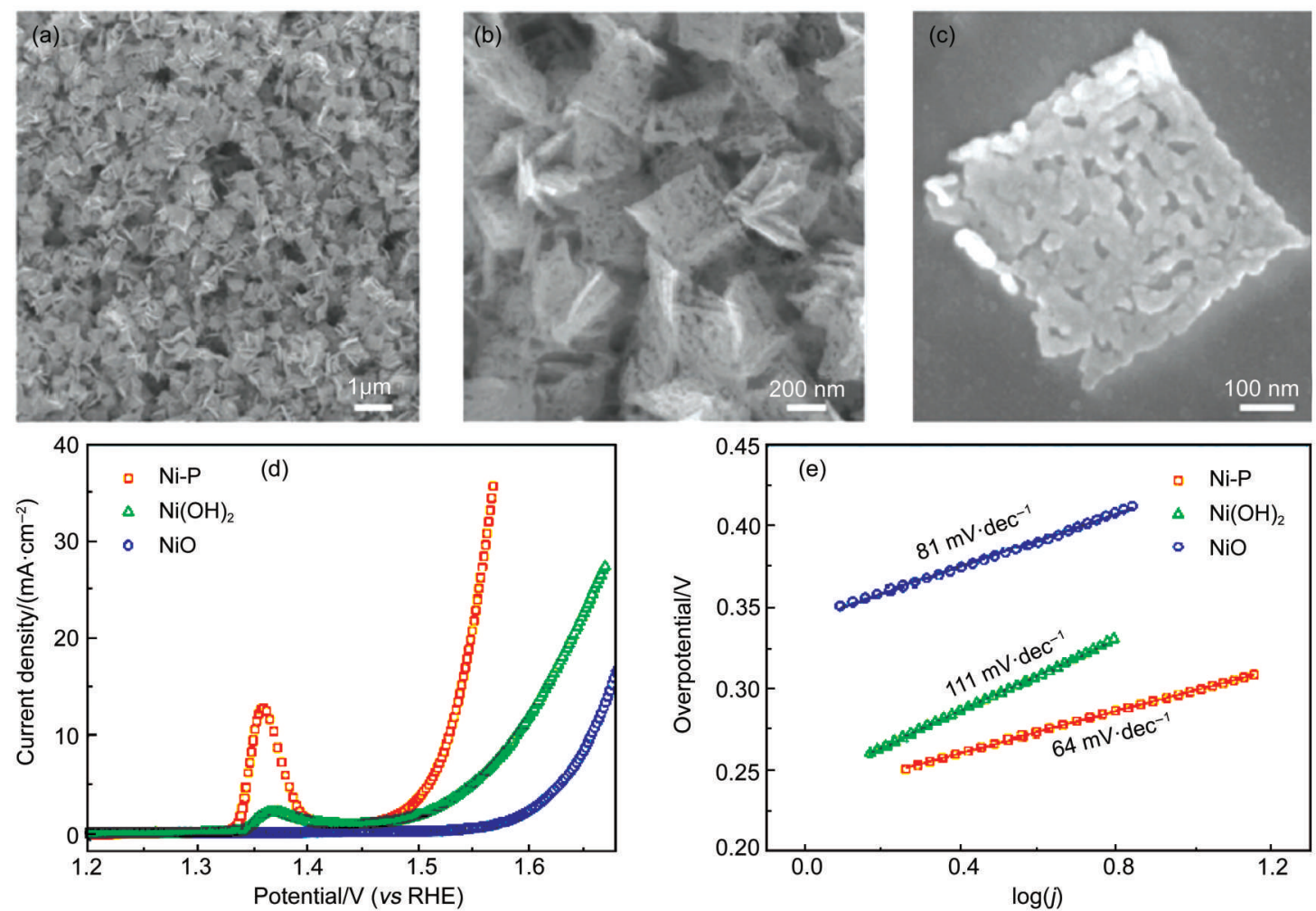

Fig.9 FESEM images of Ni-P porous nanoplates $(\mathrm{a}-\mathrm{c})$; $\mathrm{LSV}$ curves $(\mathrm{d})$ and Tafel plots $(\mathrm{e})$ of $\mathrm{Ni}-\mathrm{P}, \mathrm{Ni}(\mathrm{OH})_{2}$ and $\mathrm{NiO}$ porous nanoplates in $1.0 \mathrm{~mol} \cdot \mathrm{L}^{-1} \mathrm{KOH}^{123}$

combination of $\mathrm{MoS}_{2}$ with graphene is an efficient method to enlarge the edge exposure and improve the stability, and therefore enhance the activity in $\mathrm{HER}^{125}$. Dai's group successfully developed $\mathrm{MoS}_{2} /$ graphene hybrid using solvothermal synthesis, which exhibited superior activity with good conductivity (Tafel slope of $\sim 41 \mathrm{mV} \cdot$ decade $\left.^{-1}\right)^{104}$. Leite's group also prepared $\mathrm{MoS}_{2} /$ graphene hybrid under a relatively mild condition ${ }^{106}$. The $2 \mathrm{D}$ material formed by steps and folded edges of $\mathrm{MoS}_{2}$ layers on graphene, also showed excellent performance in HER. Zheng et al. ${ }^{126}$ prepared $\mathrm{MoS}_{2}$ /graphene hybrid using a novel solvent-evaporationassisted intercalation method, by which the sizes of $\mathrm{MoS}_{2}$ can be controlled. Notable, this composite showed better performance for HER (overpotential of ca $140 \mathrm{mV}$ and Tafel slope of $41 \mathrm{mV}$. decade ${ }^{-1}$ ) compared with other GO support $\mathrm{MoS}_{2}$ materials.

For fuel cell application, the sluggish oxygen reduction reaction (ORR) is the rate determine step for electrochemical energy conversion, which has been attracted worldwide research interests. Nitrogen doped carbon materials are proved to be potential substitute for Pt as an efficient catalyst in ORR ${ }^{127}$. Recently, Qiao's group ${ }^{128}$ reported the application of g- $\mathrm{C}_{3} \mathrm{~N}_{4} @$ carbon in ORR based on theoretical calculation. The experimental results indicated that g- $\mathrm{C}_{3} \mathrm{~N}_{4} @$ carbon performed better efficiency than Pt/C catalyst and reliable stability. More recently, 3D porous architecture was fabricated using g- $\mathrm{C}_{3} \mathrm{~N}_{4}$ nanosheets and reduced graphene oxide in aqueous solution ${ }^{129}$. As-obtained architecture possessed high surface area, multilevel porous structure, excellent electrical conductivity. It exhibited remarkable catalytic performance and excellent durability in ORR, outperformed other $g-\mathrm{C}_{3} \mathrm{~N}_{4} / \mathrm{rGO}$ composites. The excellent performance was attributed to effective electron tunneling through $\mathrm{g}-\mathrm{C}_{3} \mathrm{~N}_{4}$ barrier caused by ultrathin $\mathrm{g}$ $\mathrm{C}_{3} \mathrm{~N}_{4}$ nanosheet. This structure leads to rich electrode-electrolytegas three-phase boundaries, and shortens the electron diffusion distance from $\mathrm{rGO}$ to $\mathrm{O}_{2}$. In addition, Xiang et al. ${ }^{36,37}$ used 2D covalent organic polymers (COP) as precursor to synthesize nitrogen-doped graphene-like carbons, which exhibited excellent ORR electrocatalytic activity due to the precisely controlled heteroatom locations and pore sizes.

In addition to the reactions mentioned above, 2D materials also showed excellent performances in other electronic assisted catalytic processes. For example, Ni-Al LDH cooperated GO hybrid was developed through in-situ co-precipitation followed a reduction procedure ${ }^{130}$. The coexistence of NiAl-LDH platelets and the graphene nanosheets effectively enhanced the electrocatalytic activity for dopamine (DA) oxidation, which may have potential application of DA detection.

\subsubsection{Photocatalysis}

Photocatalysis has attracted much attention because it offers an alternative strategy for both clean energy and environmental protection. In a photocatalytic reaction, photo-generated electronhole pairs are formed on the catalyst surface. As opposed to an energy generation device where the charge carriers are collected by an electrode, in a photocatalytic reaction they are directly scavenged by different species presented in solution. However, the photogenerated electrons and holes in the excited states are very unstable and can easily recombine, dissipating the input energy as heat, resulting in low process efficiency. The $s p^{2}$-bonded carbon 
atoms, and the delocalized electrons in graphene can move freely in the network with a low resistance ${ }^{131}$. The carbon vacancies or dangling bonds in graphene can influence the electronic structure of metal atoms on graphene and improve their stability. Hence, 2D carbon-based materials are promising candidates in photocatalytic reactions. Notably, with the development of new synthesis methods, the graphene-like $\mathrm{C}_{3} \mathrm{~N}_{4}$ became a superstar for photocatalysis $^{132,133}$. In this section, we will summarize some of the recent, the most remarkable processes of photocatalysis.

Water splitting is one of the most attracting reactions in photocatalysis to transfer solar energy into chemical energy ${ }^{134}$. Xiang et al. ${ }^{135}$ prepared graphene/g- $\mathrm{C}_{3} \mathrm{~N}_{4}$ composites by combined impregnation-chemical reduction strategy. With $\sim 1.0 \%(w)$ graphene, the composite exhibited an optimum $\mathrm{H}_{2}$-production rate $\left(451 \mu \mathrm{mol} \cdot \mathrm{h}^{-1} \cdot \mathrm{g}^{-1}\right)$, which exceeded that of pure $\mathrm{g}-\mathrm{C}_{3} \mathrm{~N}_{4}$ by more than 3.07 times. It showed that graphene sheets act as electronic conductive channels to separate the photogenerated charge carriers and, therefore, to enhance the photocatalytic activity of $g-\mathrm{C}_{3} \mathrm{~N}_{4}$. To investigate the intrinsic property of $\mathrm{g}_{-} \mathrm{C}_{3} \mathrm{~N}_{4}$, Cheng's group ${ }^{136}$ synthesized $2 \mathrm{~nm} \mathrm{g-} \mathrm{C}_{3} \mathrm{~N}_{4}$ nanosheets by thermal oxidation etching, which possessed high surface area $\left(306 \mathrm{~m}^{2} \cdot \mathrm{g}^{-1}\right)$, large bandgap (by $0.2 \mathrm{eV}$ ), longer electron transport ability along the in-plane direction, and improved lifetime of photoexcited charge carriers. Therefore, the $\mathrm{g}-\mathrm{C}_{3} \mathrm{~N}_{4}$ nanosheets exhibited an enhanced activity in hydrogen revolution. Wang's group ${ }^{137}$ also reported the exfoliated g- $\mathrm{C}_{3} \mathrm{~N}_{4}$ nanosheets for visual light catalysis of hydrogen evolution. Recently, Schwinghammer et al. ${ }^{138}$ synthesized a type of novel crystalline 2D carbon nitride nanosheets by ionothermal synthesis of the layered material poly (triazine imide), PTI, followed by onestep liquid exfoliation in water. It is the first structurally welldefined, crystalline 2D carbon nitride with the highest activity toward photocatalytic water-splitting observed up to now.

Besides carbon nitrides, other 2D materials can catalyze the water splitting photoreaction. Chang et al. ${ }^{139}$ prepared $\mathrm{MoS}_{2} /$ graphene supported $\mathrm{CdS}$ composite, which showed $\mathrm{H}_{2}$ evolution rate of $1.8 \mathrm{mmol} \cdot \mathrm{h}^{-1}$ in lactic acid solution at $420 \mathrm{~nm}$. The layered $\mathrm{MoS}_{2}$ played a role as cocatalyst for $\mathrm{H}_{2}$ generation and the graphene greatly enhanced the movement of electrons. Using electrostatic assembly method, $\mathrm{Zn}$-Cr-LDH were immobilized onto RGO nanosheets to form $\mathrm{Zn}-\mathrm{Cr}-\mathrm{LDH}-\mathrm{RGO}$ nanohybrid, which showed an improved photocatalytic activity for visible light-induced $\mathrm{O}_{2}$ generation with a rate of $1.20 \mathrm{mmol} \cdot \mathrm{h}^{-1} \cdot \mathrm{g}^{-1} 140$. The high activity was attributed to the strong electronic coupling between the subnanometer-thick 2D nanostructured LDH and GO. Such structure led to the prominent increase of visible light absorption and a remarkable depression of electron-hole recombination.

Another important application of photocatalysis is the degradation of organic pollutants. The $\mathrm{g}-\mathrm{C}_{3} \mathrm{~N}_{4}$ has been a preferred choice for the methyl orange (MO) dye degradation ${ }^{141}$. This process was mainly attributed to the selective reduction of MO induced by the photogenerated electron. The same research group also reported the degradation of rhodamine B over g- $\mathrm{C}_{3} \mathrm{~N}_{4}$ and $\mathrm{TaON}$ composite with high activity originated from the enhanced electron-hole separation ${ }^{142}$. Quan's group ${ }^{143}$ fabricated graphene/g$\mathrm{C}_{3} \mathrm{~N}_{4}$ structure by a facile sonochemical approach. GO was overlaid on the surface of $\mathrm{g}_{-} \mathrm{C}_{3} \mathrm{~N}_{4}$ and acted as a separation center and electron acceptor. Wang et al. ${ }^{144}$ fabricated $\mathrm{ZnO}$ with $\mathrm{g}-\mathrm{C}_{3} \mathrm{~N}_{4}$ to hinder the electron-hole recombination and therefore increase the photocatalytic activity by 3.5 times in methyl blue (MB) degradation. Furthermore, Chen's group ${ }^{145}$ fabricated 2D porous g- $\mathrm{C}_{3} \mathrm{~N}_{4}$ nanosheets/nitrogen-doped graphene/layered $\mathrm{MoS}_{2}$ (CNNS/ $\mathrm{NRGO} / \mathrm{MoS}_{2}$ ) ternary nanojunction, which showed remarkable performance for the degradation of $\mathrm{MB}$ and removal of $\mathrm{Cr}(\mathrm{VI})$.

Apart from the above mentioned reactions, 2D carbon-based materials can be used in many other photocatalysis processes. For example, the self-assembled $\mathrm{C}_{3} \mathrm{~N}_{4}$ and layered double hydroxide LDH exhibited an improved catalytic activity for photoreduction of $\mathrm{CO}_{2}$ in aqueous solution as a result of the enrichment of carbonate anions in the interlayer of $\mathrm{LDH}^{84}$. Using GO nanosheet as a structural direct agent, a sandwich GO- $\mathrm{C}_{3} \mathrm{~N}_{4}$ hybrid was synthesized, which exhibited an enhanced photoreduction of $\mathrm{CO}_{2}$ to $\mathrm{CH}_{4}{ }^{146}$. Xu et al. ${ }^{147}$ reported that $\mathrm{g}-\mathrm{C}_{3} \mathrm{~N}_{4}$ modified $\mathrm{TiO}_{2}$ nanosheets (CTS) were prepared and employed as photoanode materials in dye-sensitized solar cells (DSSCs). The introduction of $\mathrm{g}-\mathrm{C}_{3} \mathrm{~N}_{4}$ acted as the blocking layer for electron backward recombination with electrolyte, and can increase both the open circuit voltage and short-circuit photocurrent density.

\subsection{Applications in electrical energy storage}

Due to the consumption of fossil fuels and critical environment problems, there is an urgent requirement for clean energy conversion and storage. Lithium-ion batteries and supercapacitors are two of the most promising energy storage devices. The improvement of the electrode materials is still the main strategy to promote efficiency. 2D carbon-based materials have been considered as one of the most promising alternatives as electrode materials in energy-related devices, especially the graphene-based hybrids or composites ${ }^{148}$. The reason is related to their high surface area, high conductivity, unique graphitized basal plane structure, chemical tolerance and a potentially low manufacturing $\cos ^{149,150}$. In this section, we will briefly discuss the most recently processes of the 2D carbon-based materials in the fields of lithium-ion batteries and supercapacitors, based on the materials mentioned in Section 2.

\subsubsection{Lithium-ion batteries (LIBs)}

Two dimensional nanoarchitectures are of great potential in lithium-ion batteries, due to its shortened paths for fast $\mathrm{Li}^{+}$diffusion and large exposed surface for more lithium- insertion channels ${ }^{107}$. Carbon nanosheets and its 2D hybrids containing oxides, dichalcogenides, or nitrides have been widely studied as promising electrode materials for lithium-ion batteries.

The 2D mesoporous carbon materials (mesoporous carbon nanosheets, MCNSs) with $40 \mathrm{~nm}$ thickness and $10 \mu \mathrm{m}$ width showed high capacities, superior rate performances, and robust cycle life at high rates as anodes for $\mathrm{LIBs}^{72}$. It is proved that the thicker 2D carbon nanosheets with mesopores can enhance the rate performances and simultaneously maintain its high capacities and 
robust cycle life, because they can remedy the drawbacks of thin carbon nanosheets anodes in which the diffusion of lithium ions was impeded by overlapped or folded structures. Another example was the porous carbon nanosheet materials with high nitrogen content through the Schiff-base reaction in a molten salt medium employed as anode materials in LIBs, which exhibit a high initial coulombic efficiency (ca 63.1\%), a high and constant reversible capacity of $605 \mathrm{mAh} \cdot \mathrm{g}^{-1}$ at a current density of $100 \mathrm{~mA} \cdot \mathrm{g}^{-1}$ even after 100 cycles, and a high-rate capability ${ }^{50}$. The excellent performance can be attributed to the high porosity, high nitrogen content of ca 30\% (w) and a unique two-dimensional (2D) structure.

A facile in-situ solution-phase reduced method was reported for growing $\mathrm{MoS}_{2}$ layers on a graphene nanosheet, which exhibited extraordinary capacity $\left(1300 \mathrm{mAh} \cdot \mathrm{g}^{-1}\right)$, and excellent rate capability and cycling stability as an anode material for lithium ion batteries ${ }^{103}$. Zhou et al. ${ }^{85}$ synthesized a $\mathrm{MoS}_{2}$ nanosheet-graphene nanosheet hybrid via the combination of a lithiation assisted exfoliation process and a hydrazine monohydrate vapour reduction technique. The as-obtained nanosheet-nanosheet hybrid was more robust than particle-nanosheet hybrid and exhibited much improved cycle life in LIBs. Another graphene-like $\mathrm{MoS}_{2}$ /graphene nanocomposite was prepared by hydrolysis of lithiated $\mathrm{MoS}_{2}$ $\left(\mathrm{LiMoS}_{2}\right)$ and displayed a flower-like architecture composed of exfoliated nanosheets ${ }^{87}$. Due to the synergetic effect of highly conductive graphene nanosheet (GNS) and $\mathrm{MoS}_{2}$, the reversible capacity of this $\mathrm{MoS}_{2} / \mathrm{GNS}$ nanocomposite is $\sim 1400 \mathrm{mAh} \cdot \mathrm{g}^{-1}$ in the initial cycle and remains $1351 \mathrm{mAh} \cdot \mathrm{g}^{-1}$ after 200 cycles at 100 $\mathrm{mA} \cdot \mathrm{g}^{-1}$. Furthermore, the capacity can reach $591 \mathrm{mAh} \cdot \mathrm{g}^{-1}$ even at a high current density of $1000 \mathrm{~mA} \cdot \mathrm{g}^{-1}$. Zhou et al. developed a one-step solid-phase synthesis strategy using cubic $\mathrm{NaCl}$ as template, which also created a 2D-confined space to achieve the construction of few-layer $\mathrm{MoS}_{2}$ nanosheets robustly lain on carbon nanosheets ${ }^{151}$. This novel architecture demonstrated an outstanding long-life cycling capability at high rates. Moreover, a novel $\mathrm{MoS}_{2} /$ $\mathrm{N}$-doped graphene/porous g- $\mathrm{C}_{3} \mathrm{~N}_{4}$ nanosheet multilayered nanostructure was fabricated, which exhibited excellent cycling stability ( $91 \%$ capacity after 100 cycles), high rate capability ( $83 \%$ capacity retention from 50 to $500 \mathrm{~mA} \cdot \mathrm{g}^{-1}$ ), and large capacity (more than $800 \mathrm{mAh} \cdot \mathrm{g}^{-1}$ at $100 \mathrm{~mA} \cdot \mathrm{g}^{-1}$ ) ${ }^{152}$.

Other 2D carbon-based composites have also been developed and showed excellent performance as anode materials in LIBs. For example, Hu et $a .^{79}$ applied the self-assembled Ni-Al LDH and GO hybrid as a cathode material for high-rate alkali battery. The superlattice construction enables each LDH layer being adjacent to the graphene conducting networks. Therefore, the utilization of LDH materials can be efficiently enlarged, particularly in fast charge-transfer reactions. Similarly, fabricated Ni-Mn LDH/graphene was used as an anode for $\mathrm{Li}$-ion batteries, which demonstrated a maximum capacity value of $1030 \mathrm{mAh} \cdot \mathrm{g}^{-1}$ during the first discharge ${ }^{81}$. Using a facile solvothermal/hydrothermal preparation, $\mathrm{Fe}_{2} \mathrm{O}_{3}$ nanosheets and nanoparticles were grown on graphene $^{91}$. The sheet-on-sheet composite was found to be better suitable as an anode for Li-ion battery with a high reversible capacity of $662.4 \mathrm{mAh} \cdot \mathrm{g}^{-1}$ after 100 cycles at $1000 \mathrm{~mA} \cdot \mathrm{g}^{-1}$. Fellinger' $\mathrm{s}$ group ${ }^{52}$ fabricated vertically aligned functional graphitic carbon nanosheets on metal carbide. The vertically aligned nanosheets exhibit remarkable lithium ion storage properties because of the large electrode electrolyte interface and strong interaction with the current collector.

\subsubsection{Supercapacitors}

In recent years, supercapacitors have attracted significant attention, mainly due to their high power density, long life cycle, and bridging function for the gap between traditional dielectric capacitors and batteries/fuel cells ${ }^{153}$. The capacitance and charge storage of supercapacitors mainly depend on the electrode materials. Generally, the electrode materials can be classified into three types: (1) carbon materials with large surface area; (2) conductive polymers; (3) metal oxides. In this case, many 2D carbon-based materials, including carbon nanosheets and hybrids with metal oxides, are promising candidates in supercapacitors.

Carbon nanosheets having large surface area are the most widely investigated materials for supercapacitors. Wei's group employed $\mathrm{MgO}$ as template to synthesize 3D pillared-porous carbon nanosheets ${ }^{27}$. This unique structure endowed the high-rate transportation of electrolyte ions and electrons throughout the electrode matrix, resulting in excellent electrochemical performance. Similarly, using $\mathrm{SiO}_{2}$ nanosheet as template, 2D mesoporous carbon sheet-like framework were prepared with the pore size centered at 2.2 and $15 \mathrm{~nm}^{22}$. As-obtained material exhibited excellent rate capability and cycling stability due to its unique pore structure with short ion diffusion distance. Sevilla et al. ${ }^{55}$ prepared carbon particles made up of interconnected carbon nanosheets with a thickness of $<80 \mathrm{~nm}$ by direct carbonization of organic salt, which behaved as high-performance supercapacitor electrodes in organic electrolyte with excellent power handling ability and superb robustness over long-term cycling. Moreover, mesoporous $\mathrm{N}$ - containing carbon nanosheets $(\mathrm{N}-\mathrm{CNSs}$ ) were prepared by direct carbonization of polyaniline nanosheets, which exhibited a large specific capacitance of $239 \mathrm{~F} \cdot \mathrm{g}^{-1}$ at $0.5 \mathrm{~A} \cdot \mathrm{g}^{-1}$, and the capacitance degradation of $\sim 4 \%$ over continuous 5000 charge-discharge cycles at $6 \mathrm{~A} \cdot \mathrm{g}^{-160}$. By an ionic liquid-assisted method, 2D nitrogen doped microporous carbon sheets were prepared with graphene as an inner layer with a microporous carbon coating on both sides, which show abundant micropores with narrow pores, short diffusion paths, high electrical conductive networks and good wettability ${ }^{35}$. It performed excellent rate capability, good long-term stability, high specific capacitance and high energy/ power density in supercapacitors. Wang et al..$^{39}$ developed mesoporous- carbon- coated graphite nanosheet (GNS@MC) composite, which showed a highest capacitance of $203 \mathrm{~F} \cdot \mathrm{g}^{-1}$ at $1 \mathrm{~A} \cdot$ $\mathrm{g}^{-1}$ in $6 \mathrm{~mol} \cdot \mathrm{L}^{-1} \mathrm{KOH}$ electrolyte, a good cyclic stability with $95 \%$ capacitance retention, and a high columbic efficiency of $99 \%$ after 5000 cycles. Zheng et al. ${ }^{61}$ prepared graphene/activated carbon (AC) nanosheet composite as high-performance electrode material for supercapacitor using carbonization-activation method. Besides, many sandwiched structures of carbon nanosheets have been 
developed via different methods to improve the gravimetric and volumetric performances ${ }^{32,33,62,154}$. In summary, both the porous structure and the electronic conductivity have been modified for these carbon nanosheets in order to obtain excellent performance as electrode material in supercapacitors.

The metal oxides can contribute pseudo-capacitance and thus can be used as efficient electrode materials for supercapacitors. However, its poor electronic conductivity hindered its applications. The combination of metal oxide with graphitic carbon provided a solution for this problem. Sandwich structured nanocomposites was prepared by electrostatic heteroassembly of cationic transition-metal (Co-Al, Co-Ni) LDH nanosheets and anionic $\mathrm{GO} / \mathrm{rGO}$ nanosheets ${ }^{155}$. This hybrid performed as an active electrode material for supercapacitor with a high capacity up to ca $650 \mathrm{~F} \cdot \mathrm{g}^{-1}$ as a result of hybridizing Faradaic pseudocapacitance of redoxable hydroxide nanosheets, which is approximate 6 times of increase than electric double-layer capacitance of rGO nanosheets. The Ni-Al/GO composite exhibited a maximum specific capacitance of $781.5 \mathrm{~F} \cdot \mathrm{g}^{-1}$ and excellent cycle life. Even after 200 cycle tests, the increase of the capacitance was $22.56 \%$ compared with the initial capacitance ${ }^{90}$. Co-Al hydrotalcite and graphene hybrids are also promising electrode materials, which can be produced through a simple fabrication process $s^{77,78}$. Furthermore, $\mathrm{Xie}^{\prime} \mathrm{s}$ group ${ }^{83}$ introduced the fabrication of $\delta-\mathrm{MnO}_{2}$ integrated on graphene planar hybrid as the working electrodes via a vacuum filtration process. On one hand, the planar structures of $\delta$ - $\mathrm{MnO}_{2} /$ graphene nanosheets introduced more electrochemically active surfaces for absorption/desorption of electrolyte ions. On the other hand, it brought additional interfaces at the hybridized interlayer to facilitate charge transport during charging/discharging processes. This unique structure enables great performance improvements compared to graphene-only devices for supercapacitors.

\subsection{Other applications}

As 2D carbon-based materials possess unique electronic and photonic properties, many applications have been extended in the fields of drug delivery, health care, analysis, and so on. Wang et $a l .{ }^{156}$ prepared the GO and drug intercalated layered double hydroxide hybrid film using the anionic intercalation of LDH as precursor. The combination of LDH played a role of enhancing antibacterial effect for this material. Lin et al. ${ }^{157}$ studied the potential biomedical applications of $\mathrm{g}_{-} \mathrm{C}_{3} \mathrm{~N}_{4}$. They discovered that g- $\mathrm{C}_{3} \mathrm{~N}_{4}$ nanosheets can be used as efficient photosensitizers and as $\mathrm{pH}$-responsive nanocarriers. As photosensitizers, g- $\mathrm{C}_{3} \mathrm{~N}_{4}$ nanosheets are able to generate reactive oxygen species (ROS) and kill cancer cells efficiently. As nanocarriers, $g-\mathrm{C}_{3} \mathrm{~N}_{4}$ nanosheets possess an ultrahigh drug-loading capacity owing to their high surface-to-volume ratio. These findings demonstrated the potential of $\mathrm{g}-\mathrm{C}_{3} \mathrm{~N}_{4}$ for biomedical applications.

For electric fields, using a versatile and scalable process called 'patterned regrowth', Levendorf et al. ${ }^{158}$ have prepared spatially controlled lateral junctions between electrically conductive graphene and insulating h-BN. It represents an important step towards developing atomically thin integrated circuitry and enable the fabrication of electrically isolated active and passive elements embedded in continuous, one-atom-thick sheets. Another example is the enhanced field emission behavior of $\mathrm{WS}_{2}$ - $\mathrm{RGO}$ nanocomposite $^{159}$. The enhancement may be attributed to the surface protrusions of the single-to-few layer thick sheets of the nanocomposite and an overlap of the electronic structures of $\mathrm{WS}_{2}$ and RGO.

For chemical analysis area, a highly efficient fluorosensor based on ultrathin $\mathrm{g}-\mathrm{C}_{3} \mathrm{~N}_{4}$ nanosheets was developed for detecting $\mathrm{Cu}^{2+160}$. The whole detection process can be completed within $10 \mathrm{~min}$ and the detection limit is as low as $0.5 \mathrm{nmol} \cdot \mathrm{L}^{-1}$. Chen et al. ${ }^{161}$ prepared Au hybridized $g-\mathrm{C}_{3} \mathrm{~N}_{4}$ nanosheets, which shows high specificity, good reproducibility, and long-term stability as immunosensor. Ma et al. ${ }^{162}$ reported a highly sensitive and highly selective heparin sensing platform based on protonated $\mathrm{g}-\mathrm{C}_{3} \mathrm{~N}_{4}$ nanosheets, reaching the lowest heparin detection limit of $18 \mathrm{ng} \cdot \mathrm{mL}^{-1}$.

\section{Perspective}

To summarize up, various kinds of 2D carbon-based materials have been so far synthesized, including carbon nanosheets and many hybrids/composites containing $\mathrm{O}, \mathrm{N}$, and $\mathrm{S}$ atoms. The tunable porosity, thicknesses, and composition with a wide range of physical and chemical properties makes these 2D materials very promising for further scientific studies and technological applications, especially in the fields of adsorption, catalysis, electrical energy storage, etc. Although the progress has been quite impressive, the exploration is still in its infancy and several key challenges remain to be resolved.

First of all, one opportunity in the research field of 2D carbonbased materials is the construction of novel structures through the development of assembly and doping processes. The structural engineering should aim to enhance the mechanical strength with precisely controlled pore structure and active components distribution. It is influenced by several aspects: the original pore structure of the precursors, the assembly conditions of the monomers with the templates, the atmosphere and temperatures of the pyrolysis processes, etc. Interfacial engineering at the nanoscale of 2D architectures are expected to further facilitate the mass and energy transfer. Using novel 2D precursors, such as metal-organic frameworks or $\mathrm{N}$-containing covalent organic polymers, the location of the heteroatoms is precisely determined. The surface defects and functional groups often play important role in many energy-related processes, which are often difficult to control. Therefore, exploring new doping and functionalization approaches are necessary to manipulate the surface fine structures.

Furthermore, novel properties should be further explored along with the possibility of creating and designing layered artificial 2D materials with “on-demand" structures. For example, as many 2D materials are soft and tenacious, flexible materials will be an attractive goal for wearable devices, such as the material for electrode in supercapacitor ${ }^{163}$. For energy related applications, such as electric industry, the urgent need is to exploit the availability of novel materials with metallic, semiconducting, and insulating 
properties. For applications in environment protection, e.g., analysis and elimination of pollutants in air or water, it is necessary to adjust the pore structure and surface properties through the functionalization and modification strategies.

Considering the ever-increasing demands for energy storage and environment protection, it is urgent and crucial to develop simple and efficient techniques for scale- up synthesis of 2D materials. However, due to the high surface energy and intersheet van der Waals attractions, 2D materials are easy to overlap, restack, and agglomerate. Hence, the remained difficulty is to prepare homogeneous 2D carbon-based materials in large scale with a precisely controllable thickness and microscale lateral pore structure. At this stage, most of the reported 2D structures were prepared based on colloidal process, that is one has to work with dilute solutions. The relatively poor stability of these colloidal entities with gyration radii in the micrometer range makes the large scale preparation complicated. Therefore, the development of facile and efficient routes for 2D carbon-based materials is an urgent task in the future.

\section{References}

(1) Novoselov, K. S.; Falko, V. I.; Colombo, L.; Gellert, P. R.; Schwab, M. G.; Kim, K. Nature 2012, 490, 192. doi: 10.1038/ nature 11458

(2) Xu, M. S.; Liang, T.; Shi, M. M.; Chen, H. Z. Chem. Rev. 2013, 113, 3766. doi: 10.1021/cr300263a

(3) James, D. K.; Tour, J. M. Accounts Chem. Res. 2013, 46, 2307. doi: $10.1021 / \operatorname{ar} 300127 \mathrm{r}$

(4) Pakdel, A.; Bando, Y.; Golberg, D. Chem. Soc. Rev. 2014, 43, 934. doi: $10.1039 / \mathrm{c} 3 \operatorname{cs} 60260 \mathrm{e}$

(5) Ma, R.; Sasaki, T. Adv. Mater. 2010, 22, 5082. doi: 10.1002/ adma.201001722

(6) Duerloo, K. A. N.; Li, Y.; Reed, E. J. Nat. Commun. 2014, 5, 4214. doi: $10.1038 /$ ncomms 5214

(7) Guo, X.; Zhang, F.; Evans, D. G.; Duan, X. Chem. Commun. 2010, 46, 5197. doi: 10.1039/c0cc00313a

(8) Wang, Q.; O'Hare, D. Chem. Rev. 2012, 112, 4124 doi: $10.1021 / \mathrm{cr} 200434 \mathrm{v}$

(9) Matsui, T.; Yamaguchi, A.; Takeoka, Y.; Rikukawa, M.; Sanui, K. Chem. Commun. 2002, 1094. doi: 10.1039/b200965j

(10) Varoon, K.; Zhang, X.; Elyassi, B.; Brewer, D. D.; Gettel, M.; Kumar, S.; Lee, J. A.; Maheshwari, S.; Mittal, A.; Sung, C. Y.; Cococcioni, M.; Francis, L. F.; McCormick, A. V.; Mkhoyan, K. A.; Tsapatsis, M. Science 2011, 334, 72. doi: 10.1126/ science. 1208891

(11) Roth, W. J.; Nachtigall, P.; Morris, R. E.; Cejka, J. Chem. Rev. 2014, 114, 4807. doi: 10.1021/cr400600f

(12) Zhao, Z. C.; Zhang, W. P. Acta Phys. -Chim. Sin. 2016, 32, 2475. [赵侦超, 张维萍. 物理化学学报, 2016, 32, 2475.] doi: 10.3866/PKU.WHXB201607121

(13) Zhao, Y.; Xie, Y.; Liu, Z.; Wang, X.; Chai, Y.; Yan, F. Small 2014, 10, 4521. doi: 10.1002/smll.201401549
(14) Hao, G. P.; Jin, Z. Y.; Sun, Q.; Zhang, X. Q.; Zhang, J. T.; Lu, A. H. Energy Environ. Sci. 2013, 6, 3740. doi: 10.1039/ c3ee41906a

(15) Zaera, F. ChemSusChem 2013, 6, 1797. doi: 10.1002/ cssc. 201300398

(16) Navalon, S.; Dhakshinamoorthy, A.; Alvaro, M.; Garcia, H. Chem. Rev. 2014, 114, 6179. doi: 10.1021/cr4007347

(17) Sun, Y.; Gao, S.; Lei, F.; Xie, Y. Chem. Soc. Rev. 2015, 44, 623. doi: $10.1039 / \mathrm{c} 4 \mathrm{cs} 00236 \mathrm{a}$

(18) Teramura, K.; Iguchi, S.; Mizuno, Y.; Shishido, T.; Tanaka, T. Angew. Chem. Int. Ed. 2012, 51, 8008. doi: 10.1002/ anie. 201201847

(19) Chen, Y. C.; Hsu, C. Y.; Lin, R. Y. Y.; Ho, K. C.; Lin, J. T. ChemSusChem 2013, 6, 20. doi: 10.1002/cssc.201200609

(20) Tang, H.; Hessel, C. M.; Wang, J.; Yang, N.; Yu, R.; Zhao, H.; Wang, D. Chem. Soc. Rev. 2014, 43, 4281. doi: 10.1039/ c3 $\operatorname{cs} 60437 \mathrm{c}$

(21) Zhang, L.; Wang, J.; Zhu, J.; Zhang, X.; San Hui, K.; Hui, K. N. J. Mater. Chem. A 2013, 1, 9046. doi: 10.1039/c3ta11755c

(22) Wang, Q.; Yan, J.; Wei, T.; Feng, J.; Ren, Y.; Fan, Z.; Zhang, M.; Jing, X. Carbon 2013, 60, 481. doi: 10.1016/j. carbon.2013.04.067

(23) Stephenson, T.; Li, Z.; Olsen, B.; Mitlin, D. Energy Environ. Sci. 2014, 7, 209. doi: 10.1039/c3ee42591f

(24) Sun, Q.; Guo, C. Z.; Wang, G. H.; Li, W. C.; Bongard, H. J.; Lu, A. H. Chemistry 2013, 19, 6217. doi: 10.1002/ chem.201300307

(25) Guo, S.; Dong, S. Chem. Soc. Rev. 2011, 40, 2644. doi: $10.1039 / \mathrm{c} 0 \operatorname{cs} 00079 \mathrm{e}$

(26) Liu, D.; Hu, Y. Y.; Zeng, C.; Qu, D. Y. Acta Phys. -Chim. Sin. 2016, 32, 2826. [刘 丹, 胡艳艳, 曾 超, 屈德宇. 物理化学 学报, 2016, 32, 2826.] doi: 10.3866/PKU.WHXB201609141

(27) Fan, Z.; Liu, Y.; Yan, J.; Ning, G.; Wang, Q.; Wei, T.; Zhi, L.; Wei, F. Adv. Energy Mater. 2012, 2, 419. doi: 10.1002/ aenm.201100654

(28) Yan, Y.; Cheng, Q.; Pavlinek, V.; Saha, P.; Li, C. J. Solid State Electrochem. 2013, 17, 1677. doi: 10.1007/s10008-013-2025-3

(29) Wang, H. Q.; Zhao, Z. B.; Chen, M.; Xiao, N.; Li, B. B.; Qiu, J. S. New Carbon Mater. 2014, 29, 280. doi: 10.1016/S18725805(14)60137-2

(30) Lee, J.; Kim, J.; Hyeon, T. Adv. Mater. 2006, 18, 2073. doi: 10.1002/adma.200501576

(31) Konkena, B.; Vasudevan, S. J. Phys. Chem. Lett. 2012, 3, 867. doi: $10.1021 / \mathrm{jz} 300236 \mathrm{w}$

(32) Hao, G. P.; Lu, A. H.; Dong, W.; Jin, Z. Y.; Zhang, X. Q.; Zhang, J. T.; Li, W. C. Adv. Energy Mater. 2013, 3, 1421. doi: 10.1002/aenm.201300383

(33) Wang, Q.; Yan, J.; Fan, Z. Electrochim. Acta 2014, 146, 548. doi: 10.1016/j.electacta.2014.09.036

(34) Guo, D. C.; Mi, J.; Hao, G. P.; Dong, W.; Xiong, G.; Li, W. C.; Lu, A. H. Energy Environ. Sci. 2013, 6, 652. doi: 10.1039/ 
c2ee23127a

(35) Jin, Z. Y.; Lu, A. H.; Xu, Y. Y.; Zhang, J. T.; Li, W. C. Adv. Mater. 2014, 26, 3700. doi: 10.1002/adma.201306273

(36) Xiang, Z.; Cao, D.; Huang, L.; Shui, J.; Wang, M.; Dai, L. Adv. Mater. 2014, 26, 3315. doi: 10.1002/adma.201306328

(37) Xiang, Z.; Xue, Y.; Cao, D.; Huang, L.; Chen, J. F.; Dai, L. Angew. Chem. Int. Ed. 2014, 53, 2433. doi: 10.1002/ anie. 201308896

(38) Zhang, S.; Zeng, M.; Li, J.; Li, J.; Xu, J.; Wang, X. J. Mater. Chem. A 2014, 2, 4391. doi: 10.1039/c3ta14604a

(39) Wang, L.; Mu, G.; Tian, C.; Sun, L.; Zhou, W.; Tan, T.; Fu, H. ChemSusChem 2012, 5, 2442. doi: 10.1002/cssc.201200529

(40) Wen, Z.; Wang, X.; Mao, S.; Bo, Z.; Kim, H.; Cui, S.; Lu, G.; Feng, X.; Chen, J. Adv. Mater. 2012, 24, 5610. doi: 10.1002/ adma.201201920

(41) Krishnan, D.; Raidongia, K.; Shao, J.; Huang, J. ACS Nano 2014, 8 , 449. doi: $10.1021 / \mathrm{nn} 404805 \mathrm{p}$

(42) Zheng, C.; Zhou, X.; Cao, H.; Wang, G.; Liu, Z. J. Power Sources 2014, 258, 290. doi: 10.1016/j.jpowsour.2014.01.056

(43) Xu, C.; Ning, G.; Zhu, X.; Wang, G.; Liu, X.; Gao, J.; Zhang, Q.; Qian, W.; Wei, F. Carbon 2013, 62, 213. doi: 10.1016/j. carbon.2013.05.059

(44) Liu, Y.; Cai, Q.; Li, H.; Zhang, J. J. Appl. Polymer Sci. 2013, 128, 517. doi: 10.1002/app.38208

(45) Fan, X.; Yu, C.; Yang, J.; Ling, Z.; Hu, C.; Zhang, M.; Qiu, J. Adv. Energy Mater. 2015, 5, 1401761. doi: 10.1002/ aenm.201570035

(46) Huang, Z. H.; Wang, A.; Kang, F.; Chuan, X. Mater. Lett. 2010, 64, 2444. doi: 10.1016/j.matlet.2010.07.078

(47) Deng, X.; Zhao, B. T.; Zhu, L.; Shao, Z. P. Carbon 2015, 93, 48. doi: 10.1016/j.carbon.2015.05.031

(48) Liu, X.; Fechler, N.; Antonietti, M. Chem. Soc. Rev.2013, 42, 8237. doi: $10.1039 / \mathrm{c} 3 \operatorname{cs} 60159 \mathrm{e}$

(49) Liu, X.; Antonietti, M. Carbon 2014, 69, 460. doi: 10.1016/j. carbon.2013.12.049

(50) He, B.; Li, W. C.; Lu, A. H. J. Mater. Chem. A 2015, 3, 579. doi: $10.1039 / \mathrm{c} 4 \mathrm{ta} 05056 \mathrm{~h}$

(51) Liu, X.; Giordano, C.; Antonietti, M. Small 2014, 10, 193. doi: $10.1002 / \mathrm{smll} .201300812$

(52) Zhu, J.; Sakaushi, K.; Clavel, G.; Shalom, M.; Antonietti, M.; Fellinger, T. P. J. Am. Chem. Soc. 2015, 137, 5480. doi: $10.1021 /$ jacs.5b01072

(53) Zhang, P.; Qiao, Z. A.; Zhang, Z.; Wan, S.; Dai, S. J. Mater. Chem. A 2014, 2, 12262. doi: 10.1039/c4ta02307b

(54) Chang, Y.; Antonietti, M.; Fellinger, T. P. Angew. Chem. Int. Ed. 2015, 54, 5507. doi: 10.1002/anie.201411685

(55) Sevilla, M.; Fuertes, A. B. ACS Nano 2014, 8, 5069. doi: $10.1021 / \mathrm{nn} 501124 \mathrm{~h}$

(56) Fuertes, A. B.; Sevilla, M. ACS Appl. Mater. Interfaces 2015, 7, 4344. doi: 10.1021/am508794f

(57) Bourlinos, A.; Steriotis, T.; Zboril, R.; Georgakilas, V.; Stubos,
A. J. Mater. Sci. 2009, 44, 1407. doi: 10.1007/s10853-0093263-8

(58) Peng, H.; Ma, G.; Sun, K.; Mu, J.; Lei, Z. J. Mater. Chem. A 2014, 2, 17297. doi: 10.1039/c4ta03929g

(59) Peng, H.; Ma, G.; Sun, K.; Zhang, Z.; Yang, Q.; Ran, F.; Lei, Z. J. Mater. Chem. A 2015, 3, 13210. doi: 10.1039/c5ta03034j

(60) Hou, L.; Lian, L.; Li, D.; Pang, G.; Li, J.; Zhang, X.; Xiong, S.; Yuan, C. Carbon 2013, 64, 141. doi: 10.1016/j. carbon.2013.07.045

(61) Zheng, X.; Lv, W.; Tao, Y.; Shao, J.; Zhang, C.; Liu, D.; Luo, J.; Wang, D. W.; Yang, Q. H. Chem. Mater. 2014, 26, 6896. doi: $10.1021 / \mathrm{cm} 503845 \mathrm{q}$

(62) Yan, J.; Wang, Q.; Lin, C.; Wei, T.; Fan, Z. Adv. Energy Mater. 2014, 4, 1400500. doi: 10.1002/aenm.201400500

(63) Yun, Y. S.; Park, M. H.; Hong, S. J.; Lee, M. E.; Park, Y. W.; Jin, H. J. ACS Appl. Mater. Interfaces 2015, 7, 3684. doi: 10.1021/am5081919

(64) De Arco, L. G.; Yi, Z.; Kumar, A.; Chongwu, Z. IEEE Transactions on Nanotechnology 2009, 8, 135. doi: 10.1109/tnano.2009.2013620

(65) Reina, A.; Jia, X.; Ho, J.; Nezich, D.; Son, H.; Bulovic, V.; Dresselhaus, M. S.; Kong, J. Nano Lett. 2009, 9, 30. doi: $10.1021 / \mathrm{n} 1801827 \mathrm{v}$

(66) Zhao, M. Q.; Liu, X. F.; Zhang, Q.; Tian, G. L.; Huang, J. Q.; Zhu, W. C.; Wei, F. ACS Nano 2012, 6, 10759. doi: 10.1021/ nn304037d

(67) Wang, J.; Zhu, M.; Outlaw, R. A.; Zhao, X.; Manos, D. M.; Holloway, B. C. Carbon 2004, 42, 2867. doi: 10.1016/j. carbon.2004.06.035

(68) Nishihara, H.; Simura, T.; Kobayashi, S.; Nomura, K.; Berenguer, R.; Ito, M.; Uchimura, M.; Iden, H.; Arihara, K.; Ohma, A.; Hayasaka, Y.; Kyotani, T. Adv. Funct. Mater. 2016, 26, 6418. doi: 10.1002/adfm.201602459

(69) Xu, B.; Zheng, D. F.; Jia, M. Q.; Liu, H.; Cao, G. P.; Qiao, N.; Wei, Y. P.; Yang, Y. S. Mater. Lett. 2015, 143, 159. doi: 10.1016/j.matlet.2014.12.102

(70) Tao, Y.; Endo, M.; Inagaki, M.; Kaneko, K. J. Mater. Chem. 2011, 21, 313. doi: 10.1039/c0jm01830a

(71) Wang, H.; Xu, Z.; Kohandehghan, A.; Li, Z.; Cui, K.; Tan, X.; Stephenson, T. J.; King'ondu, C. K.; Holt, C. M. B.; Olsen, B. C.; Tak, J. K.; Harfield, D.; Anyia, A. O.; Mitlin, D. ACS Nano 2013, 7, 5131. doi: 10.1021/nn400731g

(72) Li, J.; Yao, R.; Bai, J.; Cao, C. ChemPlusChem 2013, 78, 797. doi: 10.1002/cplu.201300158

(73) Choucair, M.; Thordarson, P.; Stride, J. A. Nat. Nanotech. 2009, 4, 30. doi: 10.1038/2008.365

(74) Wang, Y.; Angelatos, A. S.; Caruso, F. Chem. Mater. 2008, 20, 848. doi: $10.1021 / \mathrm{cm} 7024813$

(75) Chen, P.; Xu, K.; Li, X.; Guo, Y.; Zhou, D.; Zhao, J.; Wu, X.; Wu, C.; Xie, Y. Chem. Sci. 2014, 5, 2251. doi: 10.1039/ c3sc53303d 
(76) Chen, D.; Wang, X.; Liu, T.; Wang, X.; Li, J. ACS Appl. Mater. Interfaces 2010, 2, 2005. doi: 10.1021/am100307v

(77) Dong, X. Y.; Wang, L.; Wang, D.; Li, C.; Jin, J. Langmuir 2012, 28, 293. doi: 10.1021/1a2038685

(78) Wang, L.; Wang, D.; Dong, X. Y.; Zhang, Z. J.; Pei, X. F.; Chen, X. J.; Chen, B.; Jin, J. Chem. Commun.2011, 47, 3556. doi: $10.1039 / \mathrm{c} 0 \mathrm{cc} 05420 \mathrm{~h}$

(79) Hu, J.; Lei, G.; Lu, Z.; Liu, K.; Sang, S.; Liu, H. Chem. Commun.2015, 51, 9983. doi: 10.1039/c5cc01767j

(80) Long, X.; Li, J.; Xiao, S.; Yan, K.; Wang, Z.; Chen, H.; Yang, S. Angew. Chem. Int. Ed. 2014, 53, 7584. doi: 10.1002/ anie. 201402822

(81) Latorre-Sanchez, M.; Atienzar, P.; Abellan, G.; Puche, M.; Fornes, V.; Ribera, A.; Garcia, H. Carbon 2012, 50, 518. doi: 10.1016/j.carbon.2011.09.007

(82) Fang, Q.; Chen, B. J. Mater. Chem. A 2014, 2, 8941. doi: 10.1039/c4ta00321g

(83) Peng, L.; Peng, X.; Liu, B.; Wu, C.; Xie, Y.; Yu, G. Nano Lett. 2013, 13, 2151. doi: 10.1021/n1400600x

(84) Hong, J.; Zhang, W.; Wang, Y.; Zhou, T.; Xu, R. ChemCatChem 2014, 6, 2315. doi: 10.1002/cctc.201402195

(85) Zhou, X.; Wan, L. J.; Guo, Y. G. Chem. Commun. 2013, 49, 1838. doi: 10.1039/c3cc38780a

(86) Zeng, Z.; Yin, Z.; Huang, X.; Li, H.; He, Q.; Lu, G.; Boey, F.; Zhang, H. Angew. Chem. Int. Ed. 2011, 50, 11093. doi: 10.1002/anie.201106004

(87) Liu, Y. C.; Zhao, Y. P.; Jiao, L. F.; Chen, J. J. Mater. Chem. A 2014, 2 , 13109. doi: 10.1039/c4ta01644k

(88) Peng, J.; Weng, J. Carbon 2015, 94, 568. doi: 10.1016/j. carbon.2015.07.035

(89) Garcia-Gallastegui, A.; Iruretagoyena, D.; Gouvea, V.; Mokhtar, M.; Asiri, A. M.; Basahel, S. N.; Al-Thabaiti, S. A.; Alyoubi, A. O.; Chadwick, D.; Shaffer, M. S. P. Chem. Mater. 2012, 24, 4531. doi: 10.1021/cm3018264

(90) Gao, Z.; Wang, J.; Li, Z.; Yang, W.; Wang, B.; Hou, M.; He, Y.; Liu, Q.; Mann, T.; Yang, P.; Zhang, M.; Liu, L. Chem. Mater. 2011, 23, 3509. doi: 10.1021/cm200975x

(91) Kan, J.; Wang, Y. Sci. Rep. 2013, 3, 3502. doi: 10.1038/ srep03502

(92) Feng, J.; Sun, X.; Wu, C.; Peng, L.; Lin, C.; Hu, S.; Yang, J.; Xie, Y. J. Am. Chem. Soc. 2011, 133, 17832. doi: 10.1021/ ja207176c

(93) Feng, J.; Peng, L.; Wu, C.; Sun, X.; Hu, S.; Lin, C.; Dai, J.; Yang, J.; Xie, Y. Adv. Mater. 2012, 24, 1969. doi: 10.1002/ adma.201104681

(94) Cheng, L.; Huang, W.; Gong, Q.; Liu, C.; Liu, Z.; Li, Y.; Dai, H. Angew. Chem. Int. Ed. 2014, 53, 7860. doi: 10.1002/ anie. 201402315

(95) Ganatra, R.; Zhang, Q. ACS Nano 2014, 8, 4074. doi: 10.1021/ $\mathrm{nn} 405938 \mathrm{z}$

(96) Chen, D.; Chen, W.; Ma, L.; Ji, G.; Chang, K.; Lee, J. Y. Mater.
Today 2014, 17, 184. doi: 10.1016/j.mattod.2014.04.001

(97) Wang, H.; Feng, H. B.; Li, J. H. Small 2014, 10, 2165. doi: 10.1002/smll.201303711

(98) Tan, C. L.; Zhang, H. Chem. Soc. Rev. 2015, 44, 2713. doi: $10.1039 / \mathrm{c} 4 \mathrm{cs} 00182 \mathrm{f}$

(99) Brivio, J.; Alexander, D. T. L.; Kis, A. Nano Lett. 2011, 11, 5148. doi: 10.1021/n12022288

(100) Zhou, K. G.; Mao, N. N.; Wang, H. X.; Peng, Y.; Zhang, H. L. Angew. Chem., Int. Ed. 2011, 50, 10839. doi: 10.1002/ anie. 201105364

(101) Lee, Y. H.; Zhang, X. Q.; Zhang, W.; Chang, M. T.; Lin, C. T.; Chang, K. D.; Yu, Y. C.; Wang, J. T. W.; Chang, C. S.; Li, L. J.; Lin, T. W. Adv. Mater. 2012, 24, 2320. doi: 10.1002/ adma.201104798

(102) Altavilla, C.; Sarno, M.; Ciambelli, P. Chem. Mater. 2011, 23, 3879. doi: $10.1021 / \mathrm{cm} 200837 \mathrm{~g}$

(103) Chang, K.; Chen, W. Chem. Commun. 2011, 47, 4252. doi: $10.1039 / \mathrm{c} 1 \mathrm{cc} 10631 \mathrm{~g}$

(104) Li, Y.; Wang, H.; Xie, L.; Liang, Y.; Hong, G.; Dai, H. J. Am. Chem. Soc. 2011, 133, 7296. doi: 10.1021/ja201269b

(105) Kumar, N. A.; Dar, M. A.; Gul, R.; Baek, J. B. Mater. Today 2015, 18, 286. doi: 10.1016/j.mattod.2015.01.016

(106) Firmiano, E. G. S.; Cordeiro, M. A. L.; Rabelo, A. C.; Dalmaschio, C. J.; Pinheiro, A. N.; Pereira, E. C.; Leite, E. R. Chem. Commun.2012, 48, 7687. doi: 10.1039/c2cc33397j

(107) Liu, J. H.; Liu, X. W. Adv. Mater. 2012, 24, 4097. doi: 10.1002/ adma.201104993

(108) Jin, Z. Y.; Xu, Y. Y.; Sun, Q.; Lu, A. H. Small 2015, 11, 5151. doi: $10.1002 /$ smll.201501692

(109) Hao, G. P.; Li, W. C.; Qian, D.; Lu, A. H. Adv. Mater. 2010, 22, 853. doi: 10.1002/adma.200903765

(110) Shen, W. Z.; Hu, T. P.; Fan, W. B. RSC Adv. 2014, 4, 9126. doi: 10.1039/c3ra47946c

(111) Zhang, M.; Liu, L.; He, T.; Wu, G. T.; Chen, P. Chem.-Asian J. 2016, 11, 1849. doi: 10.1002/asia.201600396

(112) Iruretagoyena, D.; Shaffer, M. S. P.; Chadwick, D. Adsorption 2014, 20, 321. doi: 10.1007/s10450-013-9595-3

(113) Bartolomei, M.; Carmona-Novillo, E.; Giorgi, G. Carbon 2015, 95, 1076. doi: 10.1016/j.carbon.2015.08.118

(114) Zhong, Z.; Yao, J.; Low, Z. X.; Chen, R.; He, M.; Wang, H. Carbon 2014, 72, 242. doi: 10.1016/j.carbon.2014.01.072

(115) Chen, Y. Q.; Chen, L. B.; Bai, H.; Li, L. J. Mater. Chem. A 2013, 1, 1992. doi: 10.1039/c2ta00406b

(116) Nguyen, D. D.; Tai, N. H.; Lee, S. B.; Kuo, W. S. Energy Environ. Sci. 2012, 5, 7908. doi: 10.1039/c2ee21848h

(117) Liu, Y.; Ma, J. K.; Wu, T.; Wang, X. R.; Huang, G. B.; Qiu, H. X.; Li, Y.; Wang, W.; Gao, J. P. ACS Appl. Mater. Interfaces 2013, 5, 10018. doi: 10.1021/am4024252

(118) Niu, Z. Q.; Chen, J.; Hng, H. H.; Ma, J.; Chen, X. D. Adv. Mater. 2012, 24, 4144. doi: 10.1002/adma.201200197

(119) Cong, H. P.; Ren, X. C.; Wang, P.; Yu, S. H. ACS Nano 2012, 6, 
2693. doi: $10.1021 / \mathrm{nn} 300082 \mathrm{k}$

(120) Machado, B. F.; Serp, P. Catal. Sci. Technol. 2012, 2, 54 doi: 10.1039/c1cy00361e

(121) Cheng, Y.; Fan, Y.; Pei, Y.; Qiao, M. Catal. Sci. Technol. 2015, 5, 3903. doi: 10.1039/c5cy00630a

(122) Fan, X. B.; Zhang, G. L.; Zhang, F. B. Chem. Soc. Rev. 2015, 44, 3023. doi: 10.1039/c5cs00094g

(123) Yu, X. Y.; Feng, Y.; Guan, B. Y.; Lou, X. W.; Paik, U. Energy Environ. Sci. 2016, 9, 1246. doi: 10.1039/c6ee00100a

(124) Jaramillo, T. F.; Jorgensen, K. P.; Bonde, J.; Nielsen, J. H.; Horch, S.; Chorkendorff, I. Science 2007, 317, 100. doi: 10.1126/science. 1141483

(125) Lu, Q. P.; Yu, Y. F.; Ma, Q. L.; Chen, B.; Zhang, H. Adv. Mater 2016, 28, 1917. doi: 10.1002/adma.201503270

(126) Zheng, X. L.; Xu, J. B.; Yan, K. Y.; Wang, H.; Wang, Z. L.; Yang, S. H. Chem. Mater. 2014, 26, 2344. doi: 10.1021/ cm500347r

(127) Gong, K. P.; Du, F.; Xia, Z. H.; Durstock, M.; Dai, L. M. Science 2009, 323, 760. doi: 10.1126/science.1168049

(128) Zheng, Y.; Jiao, Y.; Chen, J.; Liu, J.; Liang, J.; Du, A.; Zhang, W.; Zhu, Z.; Smith, S. C.; Jaroniec, M.; Lu, G. Q.; Qiao, S. Z. J. Am. Chem. Soc. 2011, 133, 20116. doi: 10.1021/ja209206c

(129) Tian, J.; Ning, R.; Liu, Q.; Asiri, A. M.; Al-Youbi, A. O.; Sun, X. ACS Appl. Mater. Interfaces 2014, 6, 1011. doi: 10.1021/ am404536w

(130) Li, M. X.; Zhu, J. E.; Zhang, L. L.; Chen, X.; Zhang, H. M.; Zhang, F. Z.; Xu, S. L.; Evans, D. G. Nanoscale 2011, 3, 4240. doi: $10.1039 / \mathrm{c} 1 \mathrm{nr} 10592 \mathrm{~b}$

(131) Novoselov, K. S.; Geim, A. K.; Morozov, S. V.; Jiang, D.; Zhang, Y.; Dubonos, S. V.; Grigorieva, I. V.; Firsov, A. A. Science 2004, 306, 666. doi: 10.1126/science.1102896

(132) Wang, X.; Blechert, S.; Antonietti, M. ACS Catal. 2012, 2, 1596. doi: $10.1021 / \mathrm{cs} 300240 \mathrm{x}$

(133) Zheng, Y.; Liu, J.; Liang, J.; Jaroniec, M.; Qiao, S. Z. Energy Environ. Sci. 2012, 5, 6717. doi: 10.1039/c2ee03479d

(134) Wang, Y.; Wang, X.; Antonietti, M. Angew. Chem. Int. Ed. 2012, 51, 68. doi: 10.1002/anie.201101182

(135) Xiang, Q.; Yu, J.; Jaroniec, M. J. Phys. Chem. C 2011, 115, 7355. doi: $10.1021 / \mathrm{jp} 200953 \mathrm{k}$

(136) Niu, P.; Zhang, L.; Liu, G.; Cheng, H. M. Adv. Funct. Mater. 2012, 22, 4763. doi: 10.1002/adfm.201200922

(137) Yang, S.; Gong, Y.; Zhang, J.; Zhan, L.; Ma, L.; Fang, Z.; Vajtai, R.; Wang, X.; Ajayan, P. M. Adv. Mater. 2013, 25, 2452. doi: 10.1002/adma.201204453

(138) Schwinghammer, K.; Mesch, M. B.; Duppel, V.; Ziegler, C.; Senker, J.; Lotsch, B. V. J. Am. Chem. Soc. 2014, 136, 1730. doi: $10.1021 / \mathrm{ja} 411321 \mathrm{~s}$

(139) Chang, K.; Mei, Z. W.; Wang, T.; Kang, Q.; Ouyang, S. X.; Ye, J. H. ACS Nano 2014, 8, 7078. doi: 10.1021/nn5019945

(140) Gunjakar, J. L.; Kim, I. Y.; Lee, J. M.; Lee, N. S.; Hwang, S. J. Energy Environ. Sci. 2013, 6, 1008. doi: 10.1039/c3ee23989f
(141) Yan, S. C.; Li, Z. S.; Zou, Z. G. Langmuir 2009, 25, 10397. doi: 10.1021/la900923z

(142) Yan, S. C.; Lv, S. B.; Li, Z. S.; Zou, Z. G. Dalton Trans. 2010, 39, 1488. doi: 10.1039/b914110c

(143) Liao, G.; Chen, S.; Quan, X.; Yu, H.; Zhao, H. J. Mater. Chem. 2012, 22, 2721. doi: 10.1039/c1jm13490f

(144) Wang, Y.; Shi, R.; Lin, J.; Zhu, Y. Energy Environ. Sci. 2011, 4, 2922. doi: 10.1039/c0ee00825g

(145) Hou, Y.; Wen, Z.; Cui, S.; Guo, X.; Chen, J. Adv. Mater. 2013, 25, 6291. doi: 10.1002/adma.201303116

(146) Ong, W. J.; Tan, L. L.; Chai, S. P.; Yong, S. T. Chem. Commun. 2015, 51, 858. doi: 10.1039/c4cc08996k

(147) Xu, J.; Wang, G.; Fan, J.; Liu, B.; Cao, S.; Yu, J. J. Power Sources 2015, 274, 77. doi: 10.1016/j.jpowsour.2014.10.033

(148) Miller, J. R.; Outlaw, R. A.; Holloway, B. C. Science 2010, 329, 1637. doi: 10.1126/science. 1194372

(149) Han, S.; Wu, D.; Li, S.; Zhang, F.; Feng, X. Small 2013, 9 , 1173. doi: 10.1002/smll.201203155

(150) Raccichini, R.; Varzi, A.; Passerini, S.; Scrosati, B. Nat. Mater. 2015, 14, 271. doi: 10.1038/nmat4170

(151) Zhou, J. W.; Qin, J.; Zhang, X.; Shi, C. S.; Liu, E. Z.; Li, J. J.; Zhao, N. Q.; He, C. N. ACS Nano 2015, 9, 3837. doi: 10.1021/ nn506850e

(152) Hou, Y.; Li, J. Y.; Wen, Z. H.; Cui, S. M.; Yuan, C.; Chen, J. H. Nano Energy 2014, 8, 157. doi: 10.1016/j.nanoen.2014.06.003

(153) Wang, G.; Zhang, L.; Zhang, J. Chem. Soc. Rev. 2012, 41, 797. doi: $10.1039 / \mathrm{c} 1 \mathrm{cs} 15060$

(154) Luo, H.; Liu, Z.; Chao, L.; Wu, X.; Lei, X.; Chang, Z.; Sun, X. J. Mater. Chem. A 2015, 3, 3667. doi: 10.1039/c4ta05843g

(155) Ma, R. Z.; Liu, X. H.; Liang, J. B.; Bando, Y.; Sasaki, T. Adv. Mater. 2014, 26, 4173. doi: 10.1002/adma.201400054

(156) Wang, Y.; Zhang, D.; Bao, Q.; Wu, J.; Wan, Y. J. Mater. Chem. 2012, 22, 23106. doi: 10.1039/c2jm35144g

(157) Lin, L. S.; Cong, Z. X.; Li, J.; Ke, K. M.; Guo, S. S.; Yang, H. H.; Chen, G. N. J. Mater. Chem. B 2014, 2, 1031. doi: 10.1039/ c3tb21479f

(158) Levendorf, M. P.; Kim, C. J.; Brown, L.; Huang, P. Y.; Havener, R. W.; Muller, D. A.; Park, J. Nature 2012, 488, 627. doi: 10.1038/nature11408

(159) Rout, C. S.; Joshi, P. D.; Kashid, R. V.; Joag, D. S.; More, M. A.; Simbeck, A. J.; Washington, M.; Nayak, S. K.; Late, D. J. Sci. Rep. 2013, 3, 3282. doi: 10.1038/srep03282

(160) Tian, J.; Liu, Q.; Asiri, A. M.; Al-Youbi, A. O.; Sun, X. Analyt. Chem. 2013, 85, 5595. doi: 10.1021/ac400924j

(161) Chen, L.; Zeng, X.; Si, P.; Chen, Y.; Chi, Y.; Kim, D. H.; Chen, G. Analyt. Chem. 2014, 86, 4188. doi: 10.1021/ac403635f

(162) Ma, T. Y.; Tang, Y.; Dai, S.; Qiao, S. Z. Small 2014, 10, 2382. doi: $10.1002 / \mathrm{smll} .201303827$

(163) Xiao, F.; Yang, S.; Zhang, Z.; Liu, H.; Xiao, J.; Wan, L.; Luo, J.; Wang, S.; Liu, Y. Sci. Rep. 2015, 5, 9359. doi: 10.1038/ srep09359 